\title{
Effect of Cooking Methods on the Antioxidant Capacity of Foods of Animal Origin Submitted to In Vitro Digestion-Fermentation
}

\author{
Beatriz Navajas-Porras ${ }^{1}{ }^{\circledR}$, Sergio Pérez-Burillo ${ }^{1}$, Álvaro Valverde-Moya ${ }^{1}{ }^{(0)}$, Daniel Hinojosa-Nogueira ${ }^{1}{ }^{\circledR}$, \\ Silvia Pastoriza ${ }^{1,+}$ and José Ángel Rufián-Henares ${ }^{1,2, *,+}$ (i)
}

1 Departamento de Nutrición y Bromatología, Instituto de Nutrición y Tecnología de Alimentos, Centro de Investigación Biomédica, Universidad de Granada, 18071 Granada, Spain; beatriznavajas@ugr.es (B.N.-P.); spburillo@ugr.es (S.P.-B.); alvjvm@correo.ugr.es (Á.V.-M.); dhinojosa@ugr.es (D.H.-N.); spdelacueva@ugr.es (S.P.)

2 Instituto de Investigación Biosanitaria ibs.GRANADA, Universidad de Granada, 18071 Granada, Spain

* Correspondence: jarufian@ugr.es; Tel.: +34-958-24-28-41

+ These authors share the same authorship.

Citation: Navajas-Porras, B.; Pérez-Burillo, S.; Valverde-Moya, Á.; Hinojosa-Nogueira, D.; Pastoriza, S.; Rufián-Henares, J.Á. Effect of Cooking Methods on the Antioxidant Capacity of Foods of Animal Origin Submitted to In Vitro DigestionFermentation. Antioxidants 2021, 10, 445. https://doi.org/10.3390/ antiox10030445

Academic Editor:

Francesca Giampieri

Received: 18 February 2021

Accepted: 11 March 2021

Published: 13 March 2021

Publisher's Note: MDPI stays neutral with regard to jurisdictional claims in published maps and institutional affiliations.

Copyright: (c) 2021 by the authors. Licensee MDPI, Basel, Switzerland This article is an open access article distributed under the terms and conditions of the Creative Commons Attribution (CC BY) license (https:// creativecommons.org/licenses/by/ $4.0 /)$.

\begin{abstract}
The human body is exposed to oxidative damage to cells and though it has some endogenous antioxidant systems, we still need to take antioxidants from our diet. The main dietary source of antioxidants is vegetables due to their content of different bioactive molecules. However, there are usually other components of the diet, such as foods of animal origin, that are not often linked to antioxidant capacity. Still, these foods are bound to exert some antioxidant capacity thanks to molecules released during gastrointestinal digestion and gut microbial fermentation. In this work, the antioxidant capacity of 11 foods of animal origin has been studied, submitted to different culinary techniques and to an in vitro digestion and gut microbial fermentation. Results have shown how dairy products potentially provide the highest antioxidant capacity, contributing to $60 \%$ of the daily antioxidant capacity intake. On the other hand, most of the antioxidant capacity was released during gut microbial fermentation (90-98\% of the total antioxidant capacity). Finally, it was found that the antioxidant capacity of the studied foods was much higher than that reported by other authors. A possible explanation is that digestion-fermentation pretreatment allows for a higher extraction of antioxidant compounds and their transformation by the gut microbiota. Therefore, although foods of animal origin cannot be compared to vegetables in the concentration of antioxidant molecules, the processes of digestion and fermentation can provide some, giving animal origin food some qualities that could have been previously unappreciated.
\end{abstract}

Keywords: antioxidant capacity; thermal processing; animal origin food; in vitro digestion; in vitro fermentation; gut microbiota

\section{Introduction}

Global concern about the increased incidence of chronic diseases such as diabetes, obesity, cancer, and cardiovascular disease has led to paying greater attention to lifestyle habits, especially diet [1]. On the other hand, the consumption of animal origin foods has often been linked to the appearance of non-communicable diseases, particularly the consumption of red meat, processed meat, and meat derivatives [2,3]. In contrast, the consumption of plant origin foods, such as fruit and vegetables, has been linked to a protective effect against such conditions [4].

Vegetables' content in phytochemicals has been pointed out as one of the reasons behind their beneficial effect against such chronic diseases. Many of these compounds have shown great antioxidant activity and thus the potential to play a beneficial role in oxidative stress-related diseases such as cancer, cardiovascular diseases, or type 2 diabetes mellitus $[4,5]$. At the same time, vegetables' large and diverse content in biochemicals have made this type of food the object of a large variety of studies [4,5]. In contrast, the 
literature is very limited in relation to bioactive molecules or antioxidant capacity in animal origin foods such as meat, fish, eggs, or dairy products, probably due to their lack of or low quantities of such molecules, at least in comparison with vegetables. However, we now know that gastrointestinal digestion breaks down food macrostructure and helps to release smaller molecules, some of which could have antioxidant potential [6]. Such is the case of carnosine, a di-peptide with antioxidant activity as well as anti-inflammatory, neuroprotective, and anti-aging properties $[7,8]$. Therefore, other potentially antioxidant or bioactive molecules are bound to be released during digestion. In addition, other compounds with antioxidant capacity can be found in foods of animal origin, such as taurine [9] and carotenoids from animal feed [10,11].

On the other hand, undigested food passes into the large intestine, where it can be used by the gut microbiota as a fermentation substrate; such undigested food can produce compounds with biological and antioxidant activity [12]. Therefore, although food of animal origin is not characterized by a high content of bioactive molecules, it is still possible that after cooking, digestion, and fermentation, these can be generated. Additionally, cooking methodology will modify, to some degree, depending on the temperature and time applied, the chemical composition of foods. Therefore, gastrointestinal digestion and gut microbial fermentation are likely to be affected and, so too, the molecules released after such processes [13].

Accordingly, the aim of the present paper was to study the antioxidant capacity of animal origin foods, representing the main dietary categories. Different heat treatments were applied, and then they were in vitro digested and fermented. Next, the contribution of the consumption of animal origin foods to the daily intake of antioxidant capacity in Spain was calculated. Finally, the overall daily antioxidant capacity intake in Spain was calculated, also taking into account the antioxidant capacity of plant foods previously studied [14].

\section{Materials and Methods}

2.1. Chemicals

2.1.1. In Vitro Digestion and Fermentation

Cysteine, sodium di-hydrogen phosphate, sodium sulphide, resazurin, salivary $\alpha$ amylase, and pepsin from porcine bile acids (porcine bile extract) were provided by SigmaAldrich (Darmstadt, Germany). Pancreatin from porcine pancreas was provided by Alpha Aesar (Lancaster, UK).

\subsubsection{Antioxidant Capacity}

DPPH (2,2-diphenyl-1-1-picrythydrazyl), hydrochloric acid, iron (III) chloride hexahydrate, methanol, sodium acetate, TPTZ (2,4,6-Tri(2-pyridyl)-s-triazine) and Trolox $(( \pm)$-6-Hydroxy-2,5,7,8-tetramethylchromane-2-carboxylic acid) were provided by SigmaAldrich (Darmstadt, Germany).

\subsection{Samples and Cooking Conditions Applied}

Eleven animal foods were investigated belonging to the following groups: dairy, egg, fish, and meat (Table S1). Animal foods were bought in three different supermarkets (Carrefour, Dani and El Corte Inglés, Granada, Spain) and stored at room temperature (eggs) or under refrigeration for a maximum of 2 days before cooking.

The foods were submitted to different culinary treatments: boiling, frying, grilling, or roasting (Table S1). Some of them (butter, yogurt, and salmon) were also analyzed in their raw form (since they are usually consumed as raw), making it a total of 36 samples. Boiling was prepared at a rate of 5:1 (water: food) at $100{ }^{\circ} \mathrm{C}$ for $20 \mathrm{~min}$. Frying and grilling used Extra virgin olive oil (EVOO) as cooking medium. Frying was prepared at a rate of 5:1 (oil:food) at $180{ }^{\circ} \mathrm{C}$ for $8 \mathrm{~min}$. Grilling was prepared at a rate of 0.5:1 (oil:food) at $220-250^{\circ} \mathrm{C}$ for $3 \mathrm{~min}$. Roasting was prepared at $180^{\circ} \mathrm{C}$ for $10 \mathrm{~min}$. Finally, milk was commercially processed by ultra-high temperature (UHT). Cooking times and 
food:medium rates were acquired from Olmedilla-Alonso et al. [3] and adapted to our own equipment and laboratory conditions.

The utensils used for sample preparation were the following: a transportable oven $(1500 \mathrm{~W})$, fryer, frying pan and saucepan and forks, knives, spoons, and stainless steel. All these utensils were purchased from Centro Hogar Sánchez (Granada, Spain). Samples were homogenized and stored under nitrogen atmosphere at $-80^{\circ} \mathrm{C}$ in order to avoid oxidation. All analyses were carried out in duplicate.

\subsection{In Vitro Digestion and Fermentation}

Samples were subjected to an in vitro gastrointestinal and to an in vitro fermentation according to the protocol previously described [15], in triplicate. Food was added to falcon tubes together with simulated salivary fluid $(1: 1, w / v)$ composed of salts and $\alpha-$ amylase $(75 \mathrm{U} / \mathrm{mL})$. The mix was kept at $37^{\circ} \mathrm{C}$ for $2 \mathrm{~min}$ in oscillation. Right after, $10 \mathrm{~mL}$ of simulated gastric fluid was added, simulating the gastric juices content in salts and pepsin $(2000 \mathrm{U} / \mathrm{mL})$. The mix was kept at $37^{\circ} \mathrm{C}$ for $2 \mathrm{~h}$, at $\mathrm{pH} 3$ in oscillation. Finally, $20 \mathrm{~mL}$ of simulated intestinal fluid was added, simulating the intestinal juices content in salts, bile salts, and enzymes (here, we used $67.2 \mathrm{mg} / \mathrm{mL}$ pancreatine). The mix was kept at $37^{\circ} \mathrm{C}$ for $2 \mathrm{~h}$, at $\mathrm{pH} 7$, in oscillation. Once the intestinal phase was finished, tubes were kept in ice to stop enzymatic reactions and thereafter centrifuged at $3500 \mathrm{rpm}$ for $10 \mathrm{~min}$. The supernatant, which represents the fraction available for absorption in the small intestine, was stored in $1 \mathrm{~mL}$ tubes at $-80^{\circ} \mathrm{C}$ until analysis. The solid pellet, which represents the not digested fraction that goes into the large intestine, was used as in vitro fermentation substrate.

The in vitro fermentation was carried out using fecal samples from five healthy donors with no previous pathology, who had not taken antibiotics for three months prior to the assay, with a mean (Body Mass Index $=21.3$ ). Individual diets were not assessed since the objective was not to evaluate microbial communities but rather to unravel the potential antioxidant power that average people could extract from animal origin foodstuffs. The fecal samples were pooled together to reduced inter-individual variability. The fermentation was carried out at $37^{\circ} \mathrm{C}$ for $20 \mathrm{~h}$. Once the in vitro fermentation was finished, tubes were kept in ice to stop microbial reactions and thereafter centrifuged at $3500 \mathrm{rpm}$ for $10 \mathrm{~min}$. The supernatant, which represents the fraction available for absorption in the large intestine, was stored in $1 \mathrm{~mL}$ tubes at $-80^{\circ} \mathrm{C}$ until analysis. The solid pellet, which represents the fraction not fermented and excreted with feces, was appropriately discarded.

Therefore, two fractions were obtained after in vitro gastrointestinal digestion and fermentation: digestion supernatant (fraction for absorption in the small intestine), and fermentation supernatant (fraction for absorption in the large intestine). Antioxidant capacity was measured in both fractions, considering as total antioxidant capacity the sum of them.

\subsection{Antioxidant Test}

Antioxidant capacity of those two fractions was studied. The total antioxidant capacity of the two fractions was taken as the amount of total antioxidant capacity exerted by a given food. [16].

$T E A C_{D P P H}$ assay (Trolox equivalent antioxidant capacity against DPPH radicals). The method was based on the protocol of Rapisarda et al. [17] and adjusted to a microplate reader (FLUOStar Omega, BMG Labtech, Offenburg, Germany). Briefly, $280 \mu \mathrm{L}$ of DPPH reagent (prepared with $74 \mathrm{mg} \mathrm{DPPH} / \mathrm{L}$ methanol) and $20 \mu \mathrm{L}$ of digestion-fermentation supernatants were added to a 96-well plate. The antioxidant response was monitored in triplicate for one hour at $37^{\circ} \mathrm{C}$. The calibration curve was made up with Trolox at concentrations ranging from 0.01 to $0.4 \mathrm{mg} / \mathrm{mL}$ (results expressed as mmol Trolox equivalent $/ \mathrm{Kg}$ feed).

$T E A C_{F R A P}$ assay (Trolox equivalent antioxidant capacity referred to reducing capacity). The method followed the protocol of Benzie and Strain [18] to measure the ferric reducing capacity in each sample in a microplate reader (FLUOStar Omega, BMG Labtech, Offenburg, 
Germany). Briefly, $280 \mu \mathrm{L}$ of FRAP reagent (prepared daily) and $20 \mu \mathrm{L}$ of digestionfermentation supernatants were added to a 96-well plate. The antioxidant reaction was followed in triplicate for $30 \mathrm{~min}$ at $37^{\circ} \mathrm{C}$. A calibration curve was prepared with Trolox (0.01-0.4 mg/mL), and the results were expressed as mmol Trolox equivalent $/ \mathrm{Kg}$ feed.

\subsection{Daily Antioxidant Intake Calculations}

The contribution of each food group to daily dietary antioxidant capacity intake was calculated based on the amount of food per serving, the daily intake [18], and the antioxidant capacity previously measured in the samples. The antioxidant capacity of each food was related to the portion size commonly consumed in Spain [19]. Then, the overall daily antioxidant capacity intake was also studied, including both the consumption of foods of animal and plant origin. The data on antioxidant capacity provided by foods of plant origin were obtained from our previous work [20].

\subsection{Statistical Analysis}

The statistical significance of the results was checked by one-way analysis of variance (ANOVA) and subsequently by the Duncan test $(p<0.05)$. As issue for ANOVA, it had been used form of cooking (boiled, fried, grilled, raw, and roasted), sort of food (dairy, egg, fish, and meat) and sort of sample (dairy: butter, cheese, milk and yoghurt; fish: cod fish and salmon; meat: beef, chicken, lamb, and pork). Statistical analysis was performed by using boiled or raw foods and mean of all food groups because the reference groups. Pearson parametric statistic was calculated to indicate the lineal relation between antioxidant capacity at a $p$ value $<0.05$. To get the significance between the various levels among an equivalent group, the Tukey test was assigned. All the statistical analyses were performed by using Statgraphics Plus software, version 5.1.

\section{Results}

For each sample, the antioxidant capacity was measured in the supernatant fraction obtained after gastrointestinal digestion (antioxidant capacity available for absorption in the small intestine) and after fermentation (antioxidant capacity available for absorption in the large intestine). Two different antioxidant assays were applied. All antioxidant capacity values were corrected, taking into account the antioxidant capacity provided by enzymes, chemicals, and fecal inoculum.

In addition, a linear correlation was obtained by the Spearman method between the two methods. The correlation was significant $(p<0.005)$, with Spearman's rank correlation coefficient $\left(\mathrm{r}_{\mathrm{S}}\right)$ around 0.8 .

\subsection{Samples by Type of Cooking}

The types of cooking compared were boiled, fried, grilled, roasted, and UHT. They were compared with each other as well as with respect to the raw food (Table S2).

\subsubsection{Gastrointestinal Digestion Supernatant}

Regarding TEAC $_{\text {DPPH }}$, raw foods showed significantly $(p<0.05)$ lower antioxidant capacity than all types of cooking, except for UHT, which was not significant (Figure 1A).

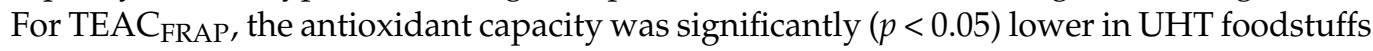
than that of raw foods, but no significance was found for the other types of cooking (Figure 1B). In addition, when comparing the means of the different cooking methods, statistically significant differences were found (ANOVA paired comparison; $p<0.05$; $\left.\mathrm{TEAC}_{\mathrm{DPPH}}\right)$ for fried foods, being more antioxidant than raw foods. 


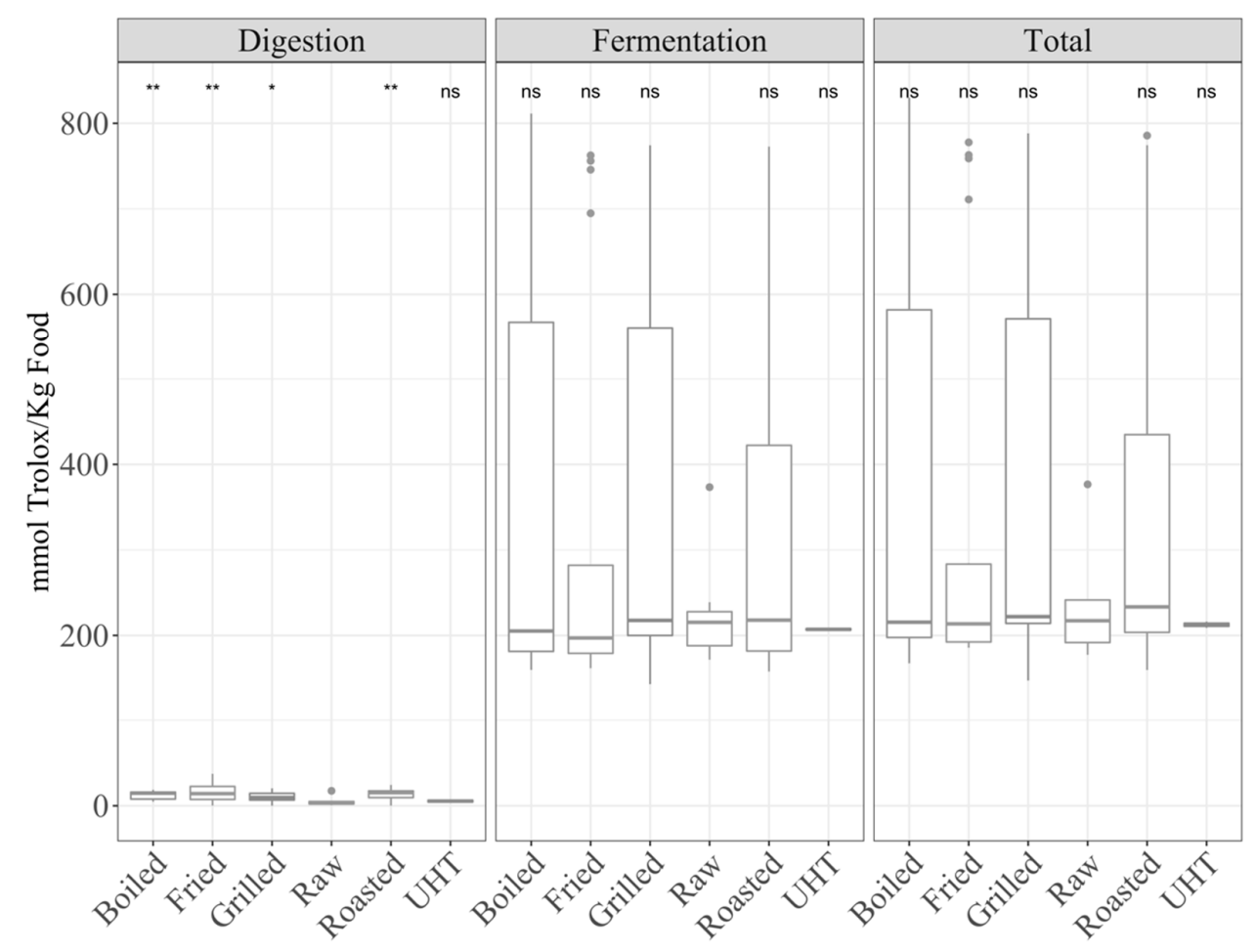

(A)

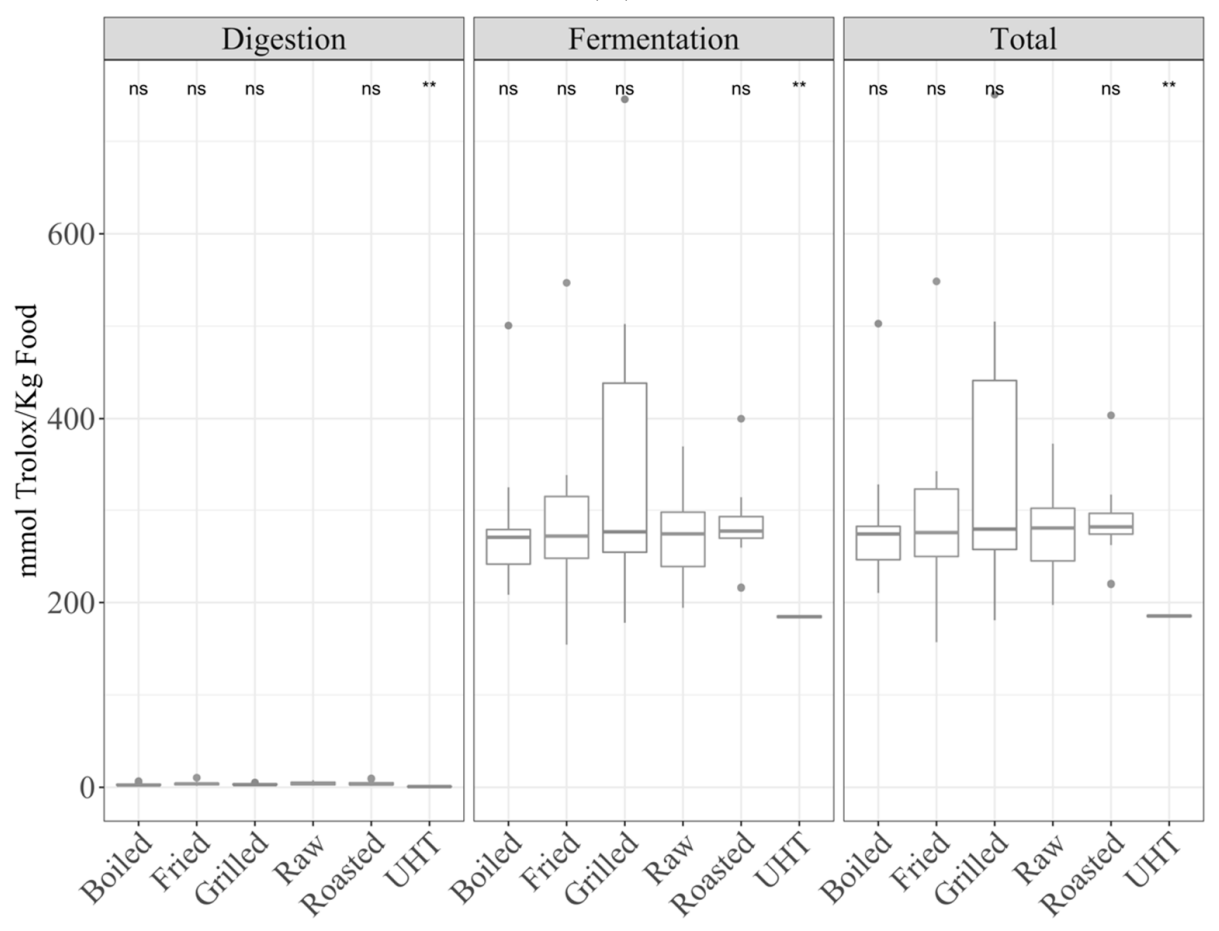

(B)

Figure 1. Antioxidant capacity of food of animal origin (butter, cheese, milk, yogurt, egg, cod fish, salmon, beef, chicken, lamb, and pork) obtained after in vitro digestion and fermentation, depending on the cooking technique ((A) Trolox capacity against DPPH radicals (TEAC $\left.\mathrm{DPPH}_{\mathrm{D}}\right),(\mathrm{B})$ for Trolox equivalent antioxidant capacity referred to reducing capacity $\left(\right.$ TEAC $\left.\left._{\mathrm{FRAP}}\right)\right)$. Statistical analysis was performed through ANOVA using raw foods as the reference group. Statistic labels: ${ }^{*}: p<0.05,{ }^{* *}: p<0.01$, ns: not significant. 


\subsubsection{Fermentation Supernatant and Total Antioxidant Capacity}

Regarding $\mathrm{TEAC}_{\mathrm{DPPH}}$, there were no significant differences (Figure $1 \mathrm{~A}$ ). TEAC $\mathrm{FRAP}_{\mathrm{F}}$ of UHT showed a significantly $(p<0.05)$ lower antioxidant capacity than raw foods (Figure 1B). No other differences with raw foods were found.

In addition, when comparing the means of the different cooking methodologies, the following significant differences were found (ANOVA paired comparison; $p<0.05$ ): for $\mathrm{TEAC}_{\mathrm{DPPH}}$, raw foods were more antioxidant than boiled; for TEAC $\mathrm{FRAP}_{\mathrm{FHT}}$ were less antioxidant than the rest of cooked foods except roast ones. For both fractions and for the total antioxidant capacity, the significance in ANOVA paired comparison for TEAC $C_{F R A P}$, stated that UHT foods were less antioxidant.

\subsection{Samples by Type of Food}

The samples to be compared were divided into four groups: dairy products (composed of butter, cheese, milk and yogurt), eggs, meats (including beef, chicken, lamb, and pork) and fish, which included salmon and cod fish (Table S3).

\subsubsection{Gastrointestinal Digestion Supernatant}

Regarding $\mathrm{TEAC}_{\mathrm{DPPH}}$, meat showed a significantly $(p<0.05)$ higher antioxidant capacity than the rest of the groups. On the other hand, the antioxidant capacity of dairy products was significantly lower than the average antioxidant capacity of the other

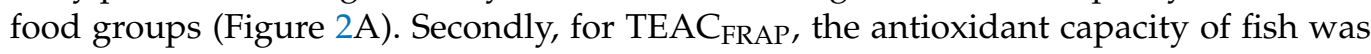
significantly $(p<0.05)$ lower to the other food groups, while that of eggs was the highest (Figure 2B).

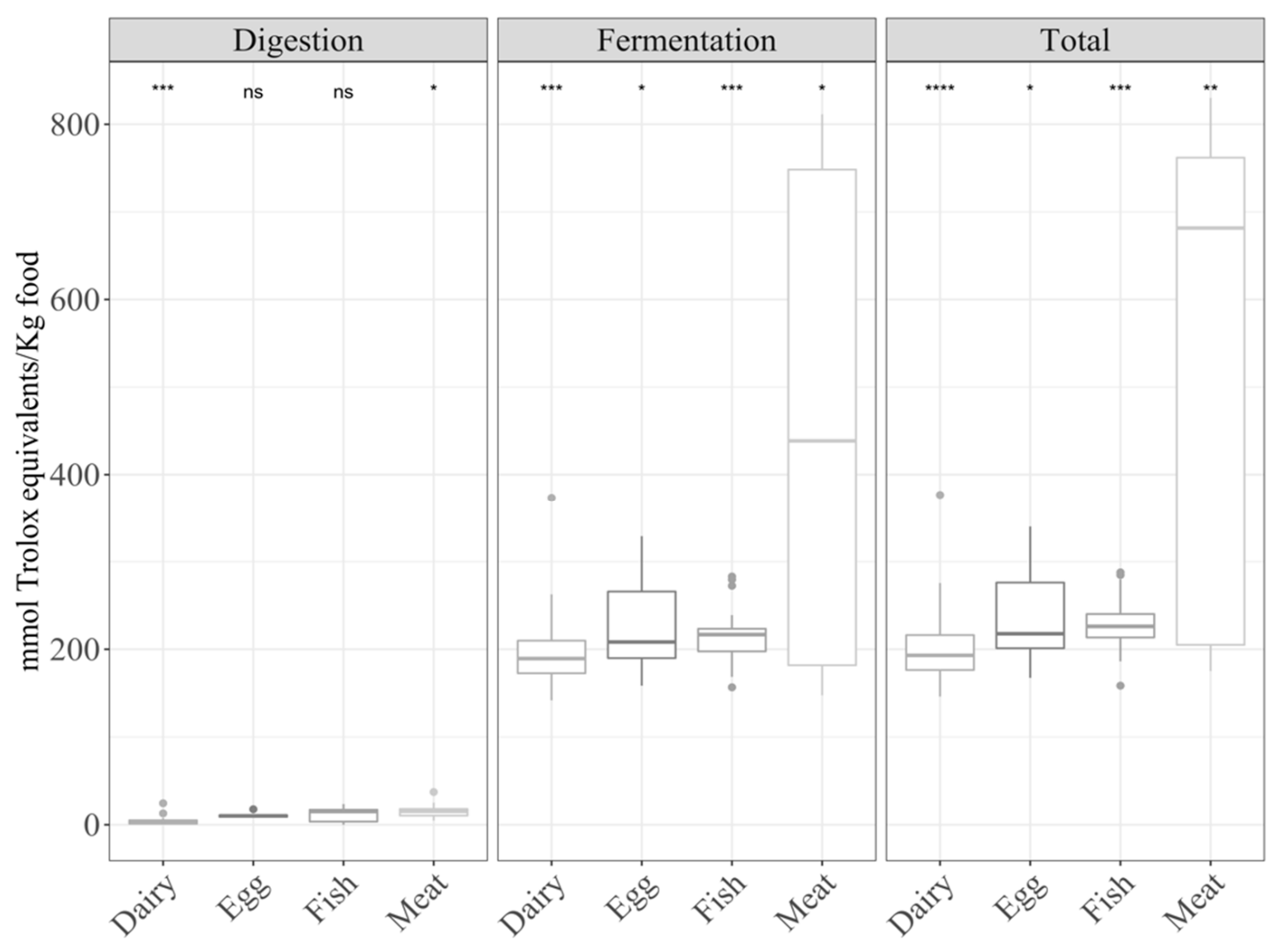

(A)

Figure 2. Cont. 


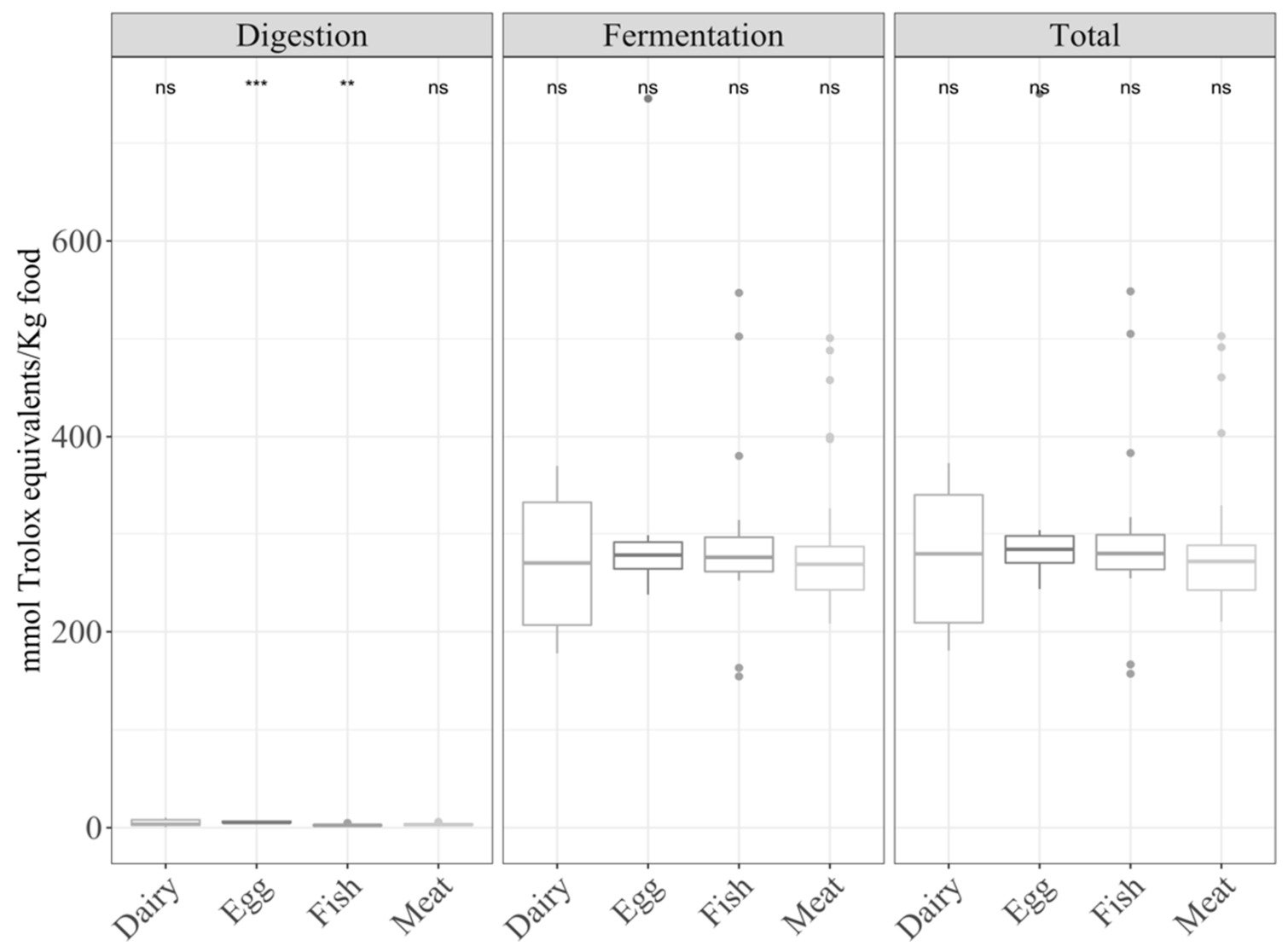

(B)

Figure 2. Antioxidant capacity of foods of animal origin (butter, cheese, milk, yogurt, egg, cod fish, salmon, beef, chicken, lamb, and pork) obtained after in vitro digestion and fermentation, depending on the food group ((A) TEAC $\mathrm{DPPH}_{\text {and }}(\mathbf{B})$ TEAC $C_{\text {FRAP }}$. Statistical analysis was performed via ANOVA using the mean antioxidant capacity of all food groups as the reference group. Statistic labels: ${ }^{*}: p<0.05,{ }^{* *}: p<0.01,{ }^{* * *}: p<0.001,{ }^{* * * *}: p<0.0001$, ns: not significant.

\subsubsection{Fermentation Supernatant and Total Antioxidant Capacity}

In the case of $\mathrm{TEAC}_{\mathrm{DPPH}}$, the fermentation supernatant and total antioxidant capacities were significantly (ANOVA paired comparison; $p<0.05$ ) higher in meat, whereas they were lower in dairy products, egg, and fish compared with the mean antioxidant capacity of all

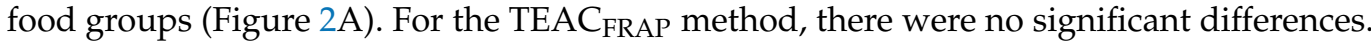

Figure 3 shows the contribution of each fraction to the total antioxidant capacity. For both methods, the contribution of the digestion fraction was negligible or non-existent, with the fermentation fraction being the most important one.

\subsection{Specific Group Analysis}

The antioxidant capacity within each of the above-mentioned food groups (dairy, fish, and meat) was also analyzed. Each group was studied by cooking method and by type of food. Dairy consisted of butter, cheese, milk, and yoghurt; fish consisted of cod fish and salmon and meat consisted of beef, chicken, lamb, and pork (Table S1). 


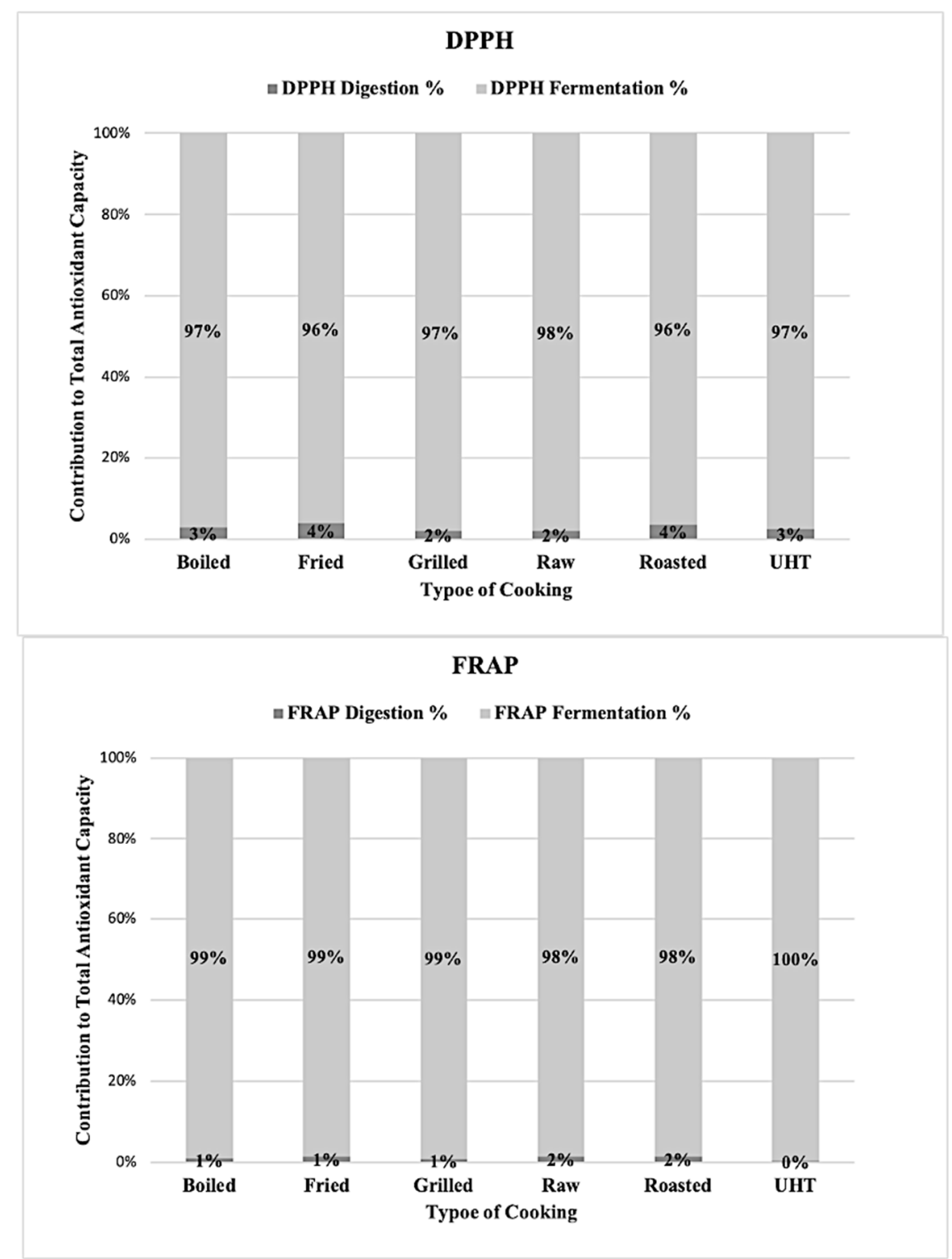

Figure 3. Contribution to the total antioxidant capacity of the fractions obtained after in vitro digestion depending of the cooking technique with the two antioxidant assays.

\subsubsection{Dairy}

By cooking (Table S4). Regarding $\mathrm{TEAC}_{\mathrm{DPPH}}$ (Figure $4 \mathrm{~A}$ ), raw dairy products showed higher antioxidant capacity than roasted ones in the digestion fraction. However, raw products showed a significantly $(p<0.05)$ higher antioxidant value than grilled products in the fermentation fraction, as well as a higher total antioxidant capacity. Regarding

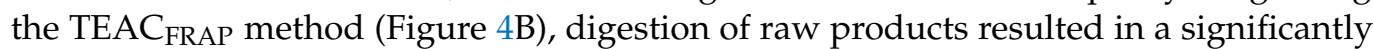
higher antioxidant capacity than UHT, but lower than roasted foods. On the other hand, fermentation of raw products released significantly more antioxidant power than UHT, which resulted as well in a higher total antioxidant capacity.

By sample (Table S5). In the case of $\mathrm{TEAC}_{\mathrm{DPPH}}$ (Figure $4 \mathrm{C}$ ), comparing the means of the different dairy products (ANOVA paired comparisons, $p<0.05$ ), butter antioxidant capacity was higher than that of cheese in the fermented fraction and total antioxidant

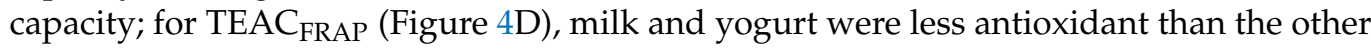
dairy products for the fermented fraction and total antioxidant capacity. 


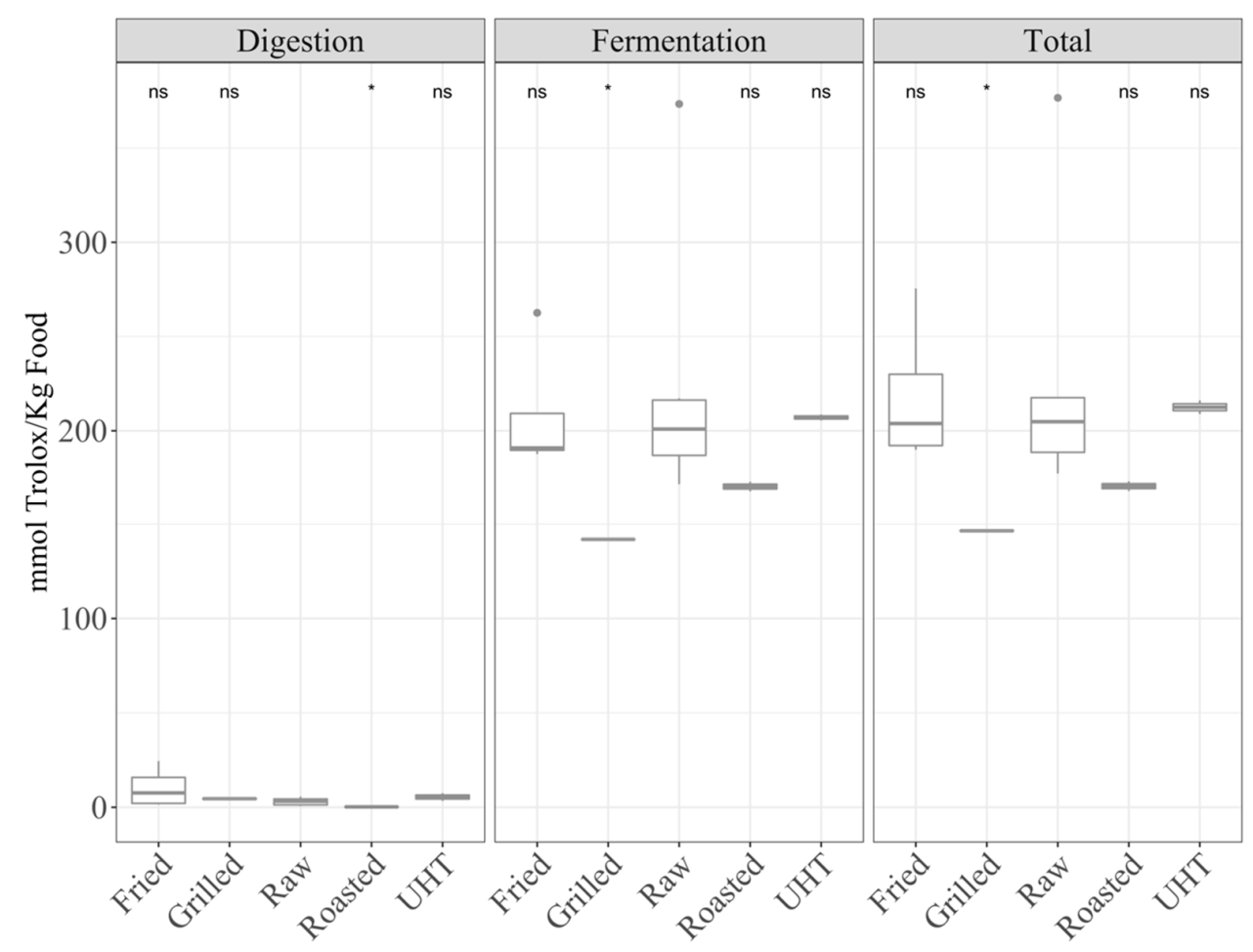

(A)

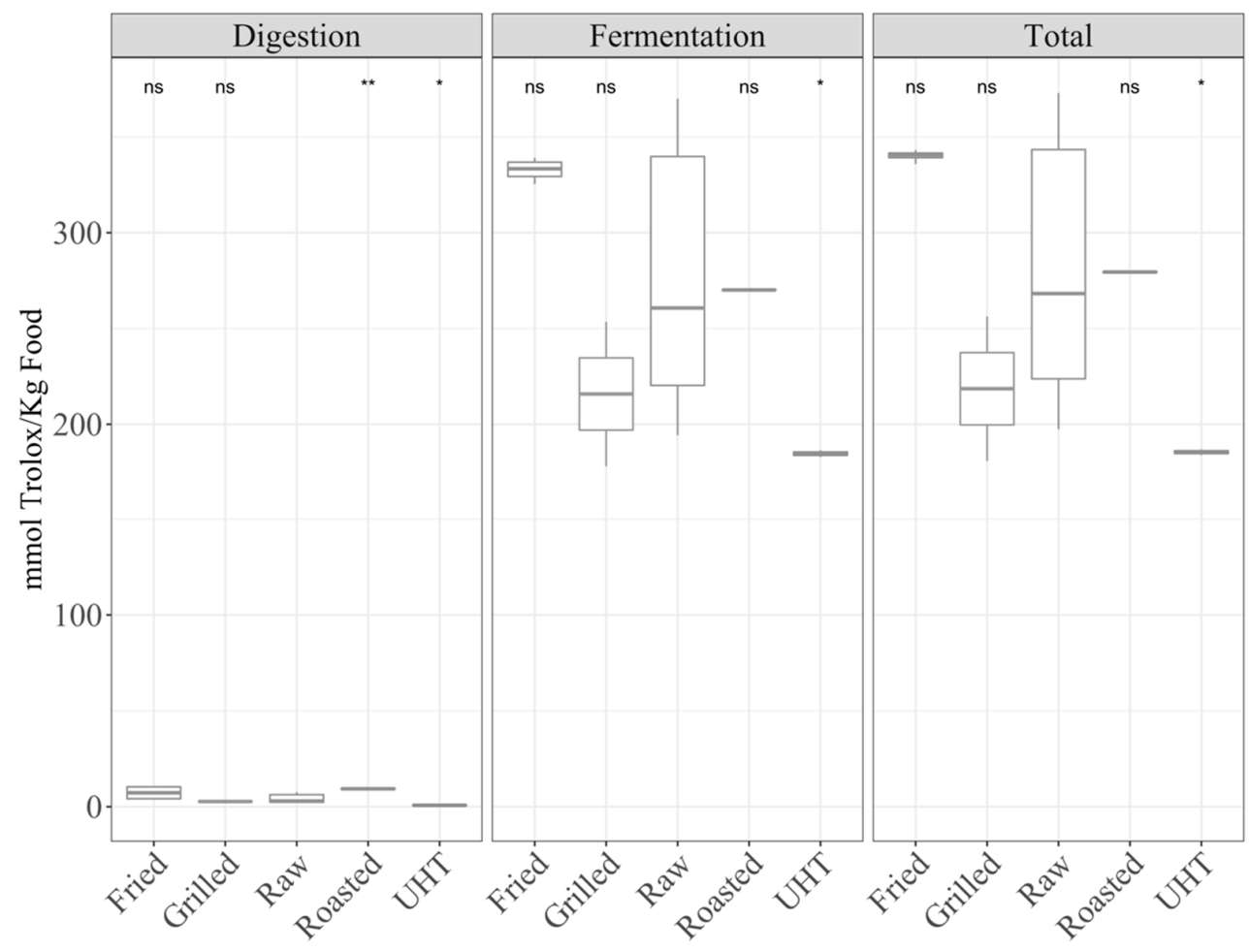

(B)

Figure 4. Cont. 


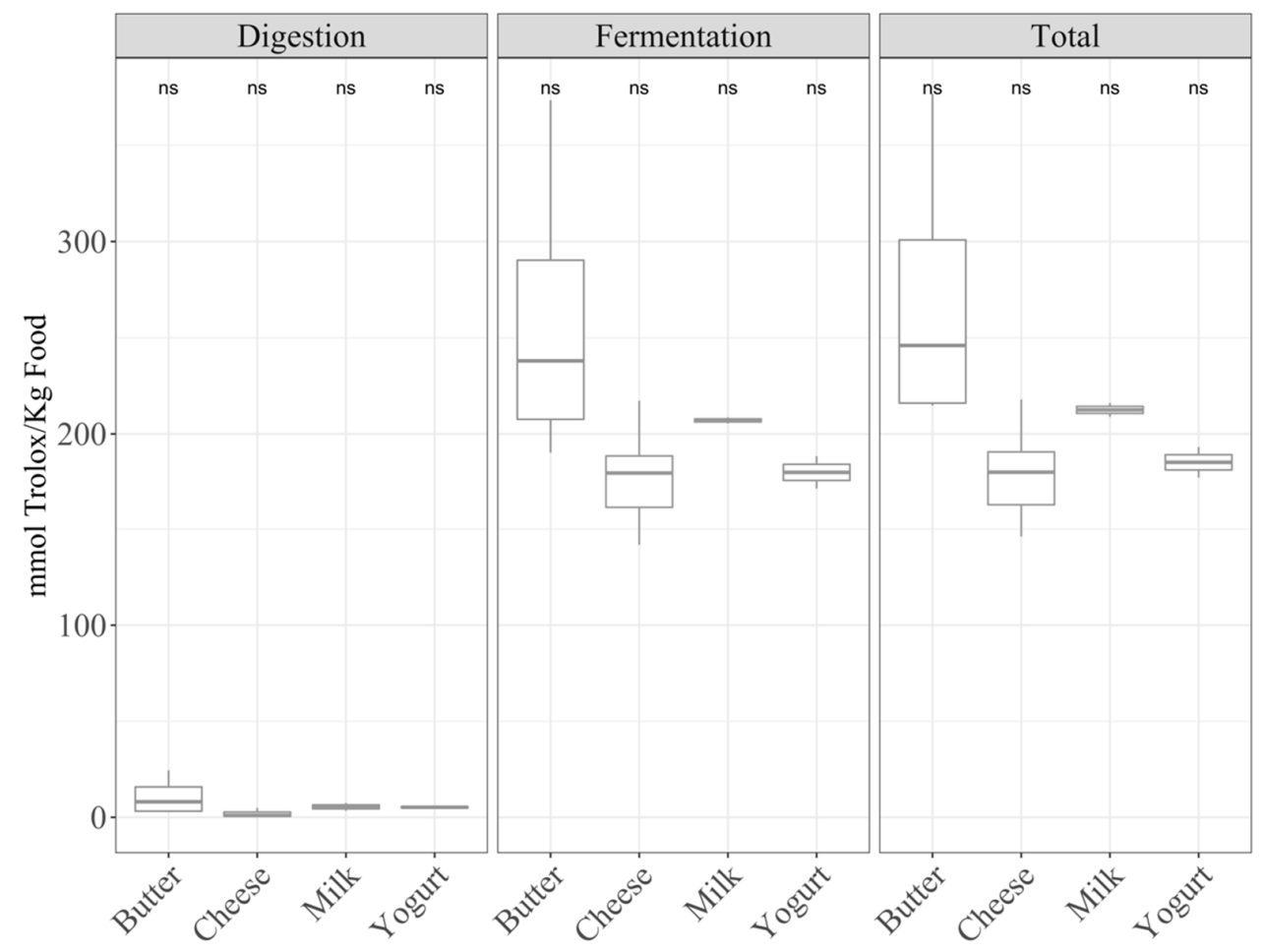

(C)

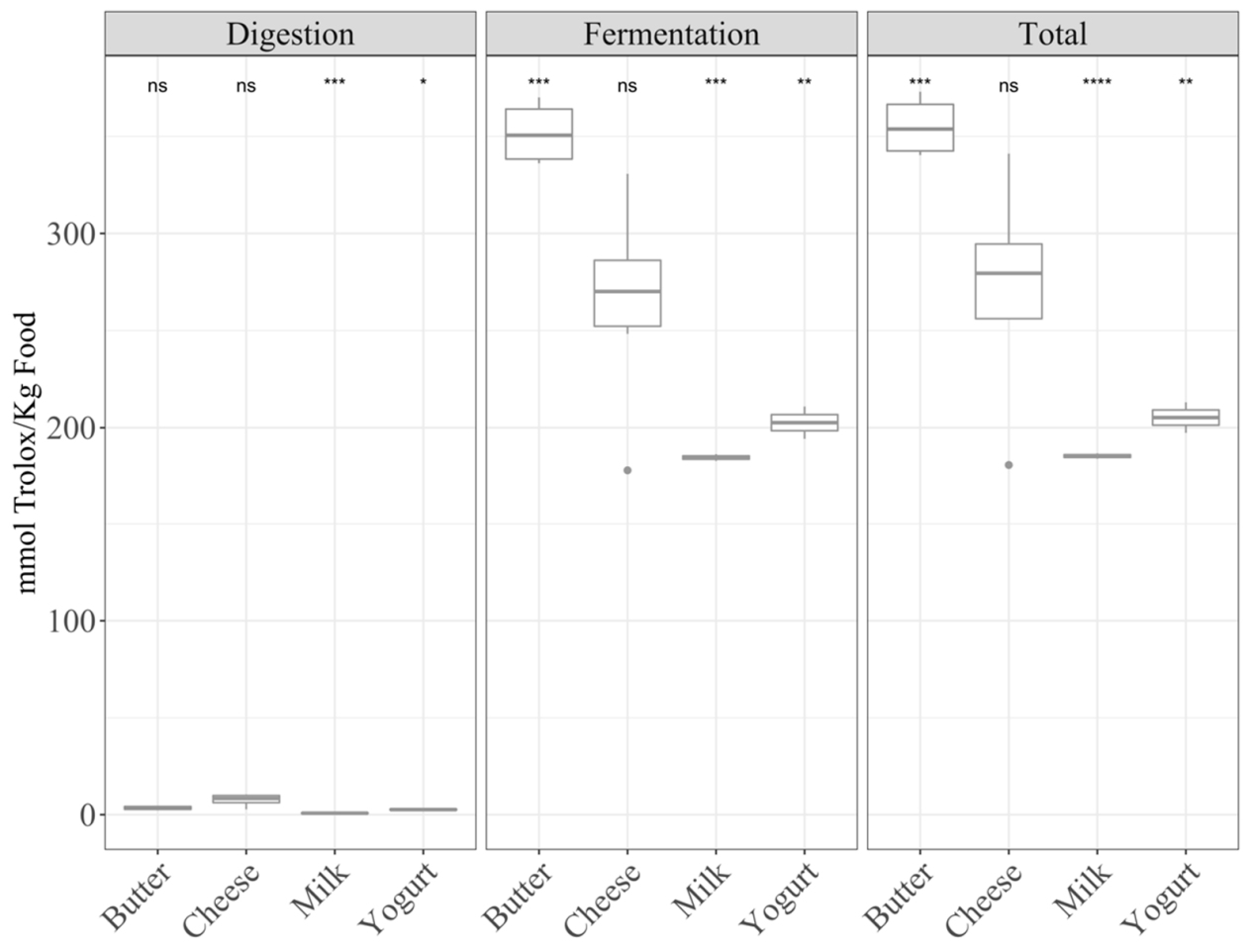

(D)

Figure 4. Antioxidant capacity of digested-fermented daily products (butter, cheese, milk and yogurt) depending on the cooking technique $\left((\mathbf{A}) \mathrm{TEAC}_{\mathrm{DPPH}},(\mathbf{B}) \mathrm{TEAC}_{\mathrm{FRAP}}\right)$ and depending on the sample $\left((\mathbf{C}) \mathrm{TEAC}_{\mathrm{DPPH}},(\mathrm{D}) \mathrm{TEAC}_{\mathrm{FRAP}}\right)$. Statistical analysis was performed through ANOVA using raw vegetables to figures $\mathrm{A}$ and $\mathrm{B}$ or mean of all food groups to figures $\mathrm{C}$ and $\mathrm{D}$ as the reference group. Statistic labels: ${ }^{*}: p<0.05,{ }^{* *}: p<0.01,{ }^{* * *}: p<0.001,{ }^{* * * *}: p<0.0001$, ns: not significant. 


\subsubsection{Fish}

By cooking (Table S6). No significant differences were found for the TEAC $\mathrm{DPPH}_{\mathrm{DP}}$ assay (Figure $5 \mathrm{~A}$ ); for TEAC $\mathrm{CRAP}_{\mathrm{FR}}$ (Figure $5 \mathrm{~B}$ ), the digested fraction of raw fish was more antioxidant than cooked ones when comparing the means of the different samples (ANOVA paired comparisons, $p<0.05$ ). In the case of the fermented fraction and total antioxidant capacity, there were no significant differences, only for $\mathrm{TEAC}_{\mathrm{DPPH}}$, where boiled fish was less antioxidant than raw.

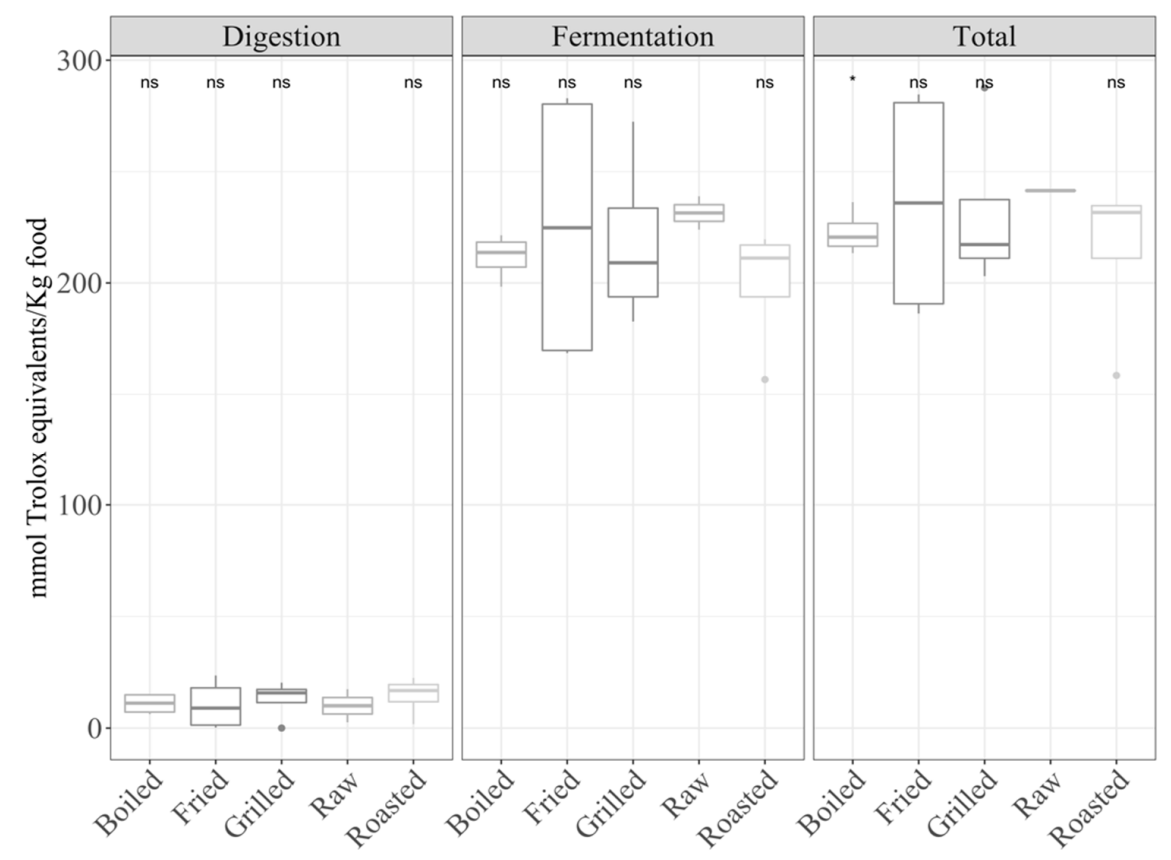

(A)

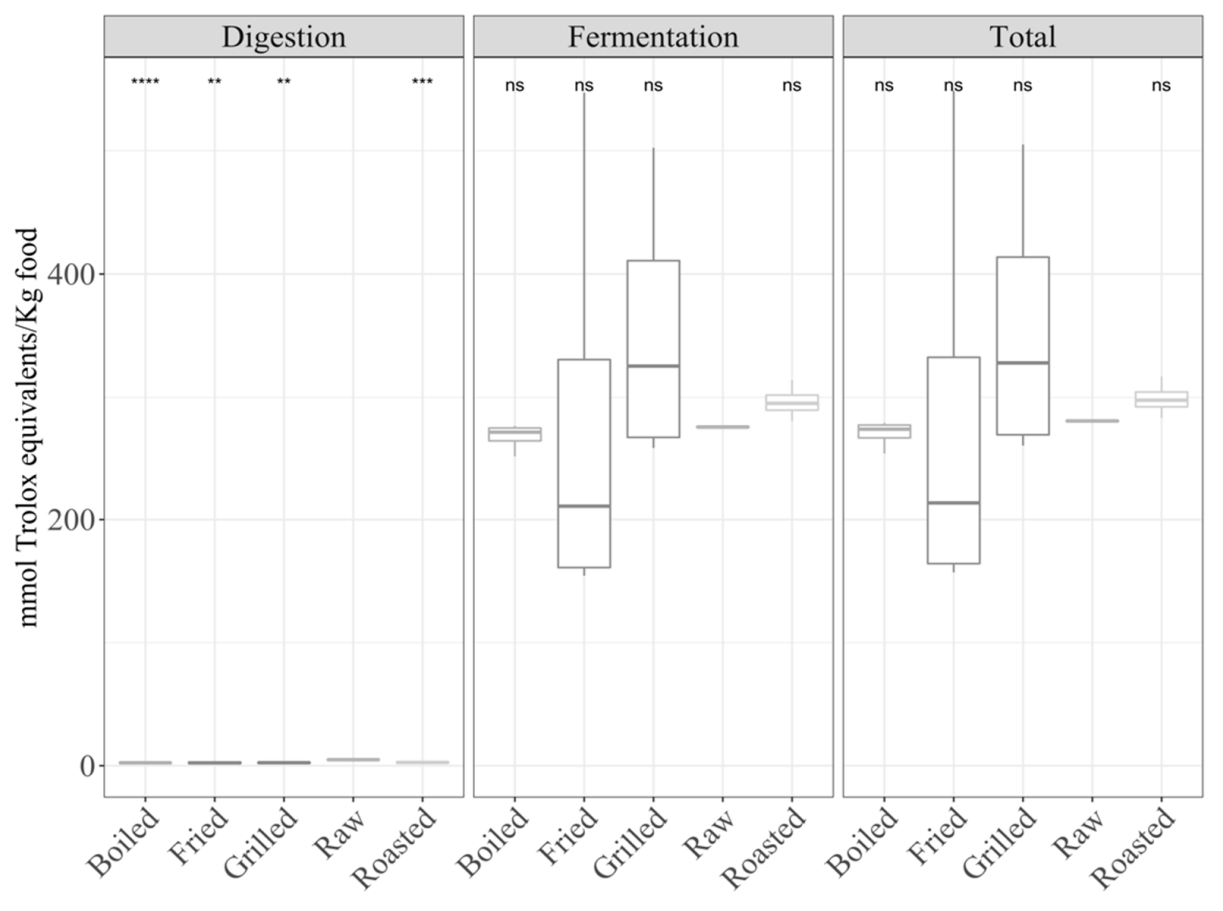

(B)

Figure 5. Cont. 


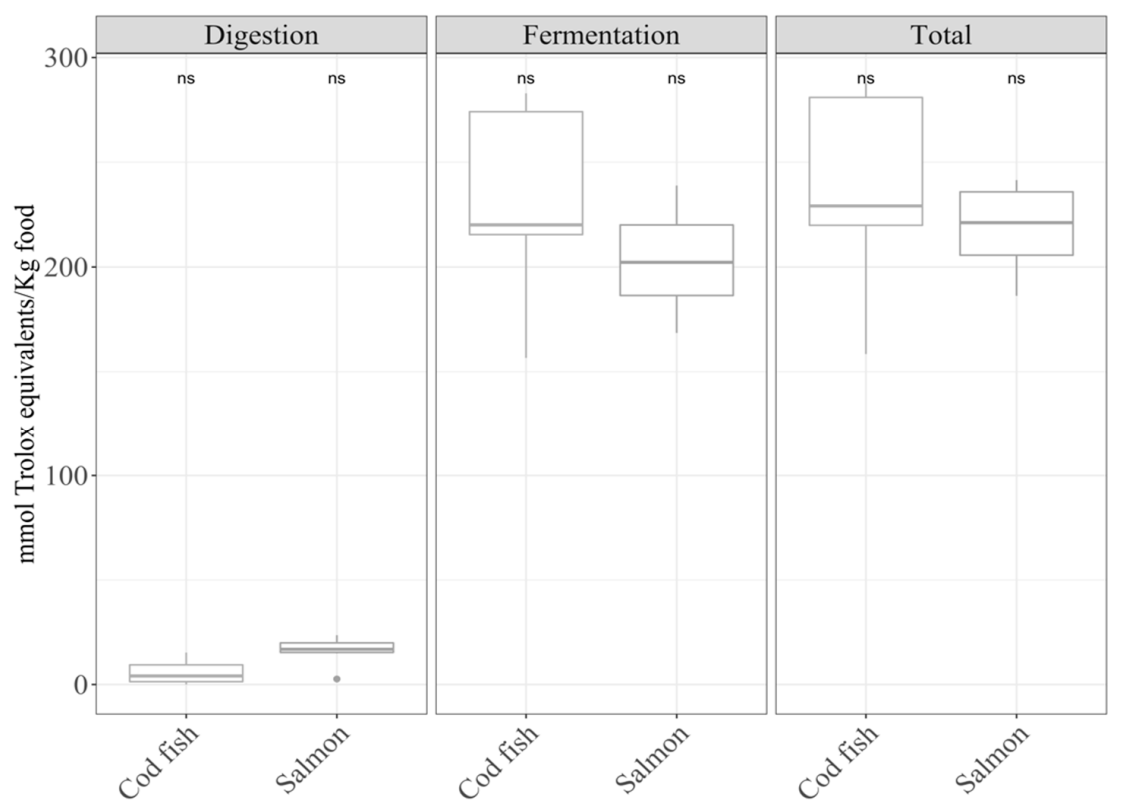

(C)

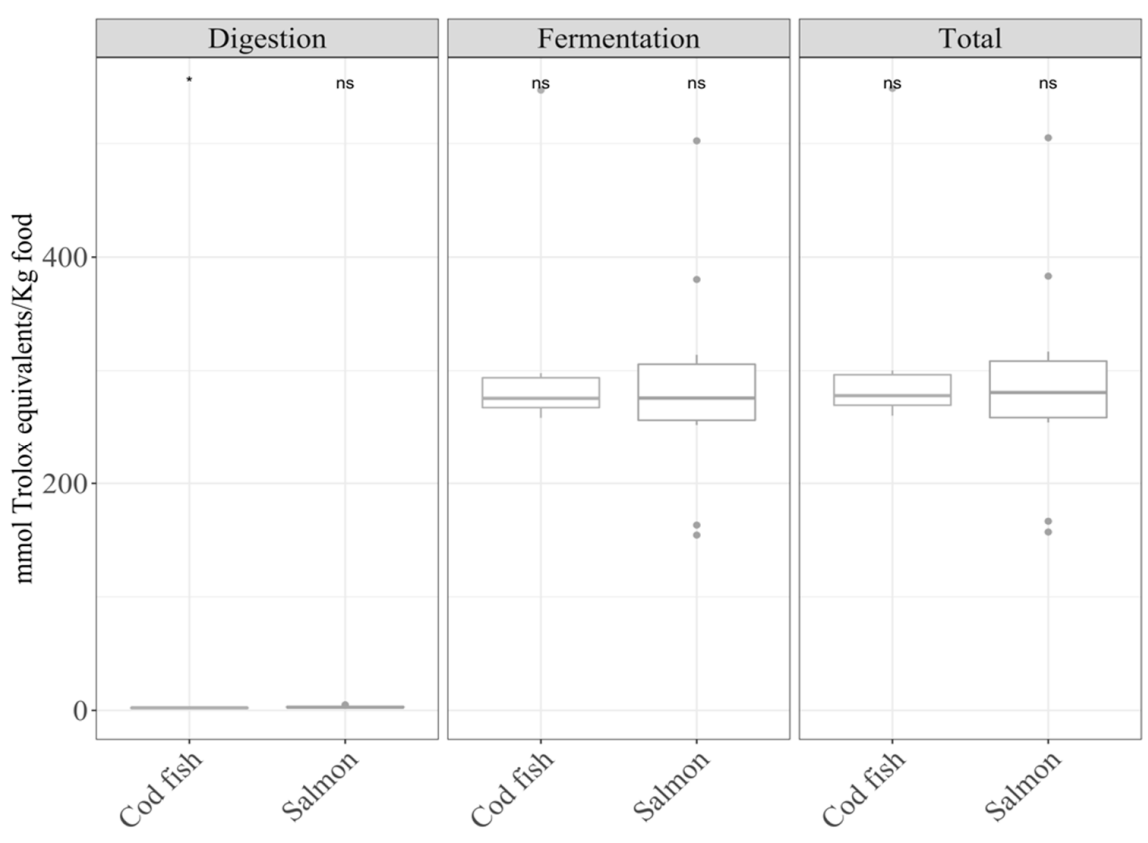

(D)

Figure 5. Antioxidant capacity of digested-fermented fish (cod fish and salmon) depending on the cooking technique

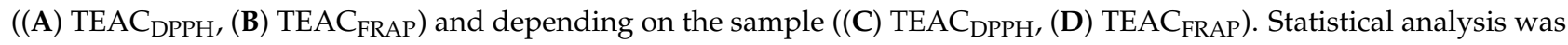
performed through ANOVA using raw vegetables or mean of all food groups as the reference group. Statistic labels: ${ }^{*}: p<0.05,{ }^{* *}: p<0.01,{ }^{* * *}: p<0.001,{ }^{* * * *}: p<0.0001$, ns: not significant.

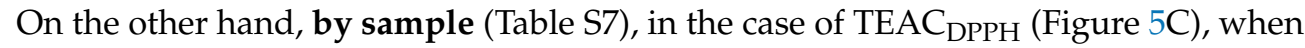
comparing the means of the different samples (ANOVA paired comparisons, $p<0.05$ ), salmon (blue fish) was more antioxidant than cod fish (white fish) after digestion; for the 


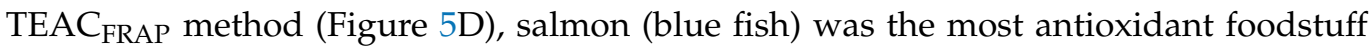
when comparing means of different samples (ANOVA paired comparisons, $p<0.05$ ).

\subsubsection{Meat}

No significant differences were found in meat by cooking (Table S8), either for $\mathrm{TEAC}_{\mathrm{DPPH}}$ (Figure $6 \mathrm{~A}$ ) or for TEAC $\mathrm{C}_{\mathrm{FAP}}$ (Figure $6 \mathrm{~B}$ ). On the other hand, by sample (Table S9), for TEAC $\mathrm{CPPH}_{\mathrm{DPH}}$ (Figure $6 \mathrm{C}$ ) lamb and pork were significantly more antioxidant than beef and chicken after fermentation, as well as the total antioxidant capacity. In the

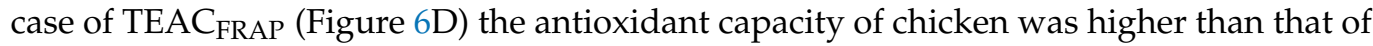
lamb, both total antioxidant capacity and after in vitro fermentation. Differences between red and white meat were analyzed (Table S10) and not many significant differences were observed (Figure 6E,F).

The antioxidant capacities of meats and fish were also compared. In this sense, fish showed significantly lower antioxidant capacity $\left(\mathrm{TEAC}_{\mathrm{DPPH}}\right)$ than meat in the fermentation fraction and total antioxidant capacity.

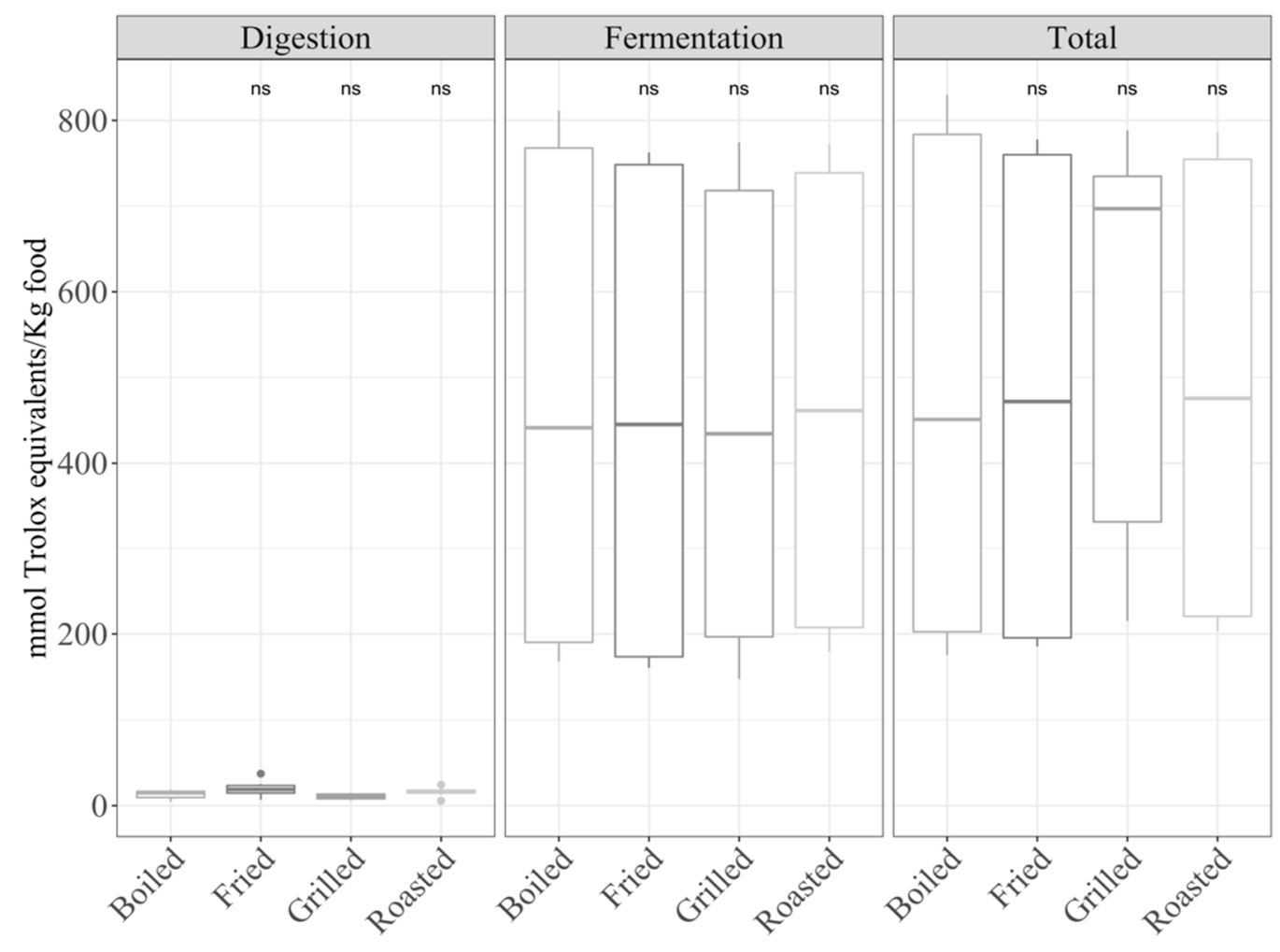

(A)

Figure 6. Cont. 


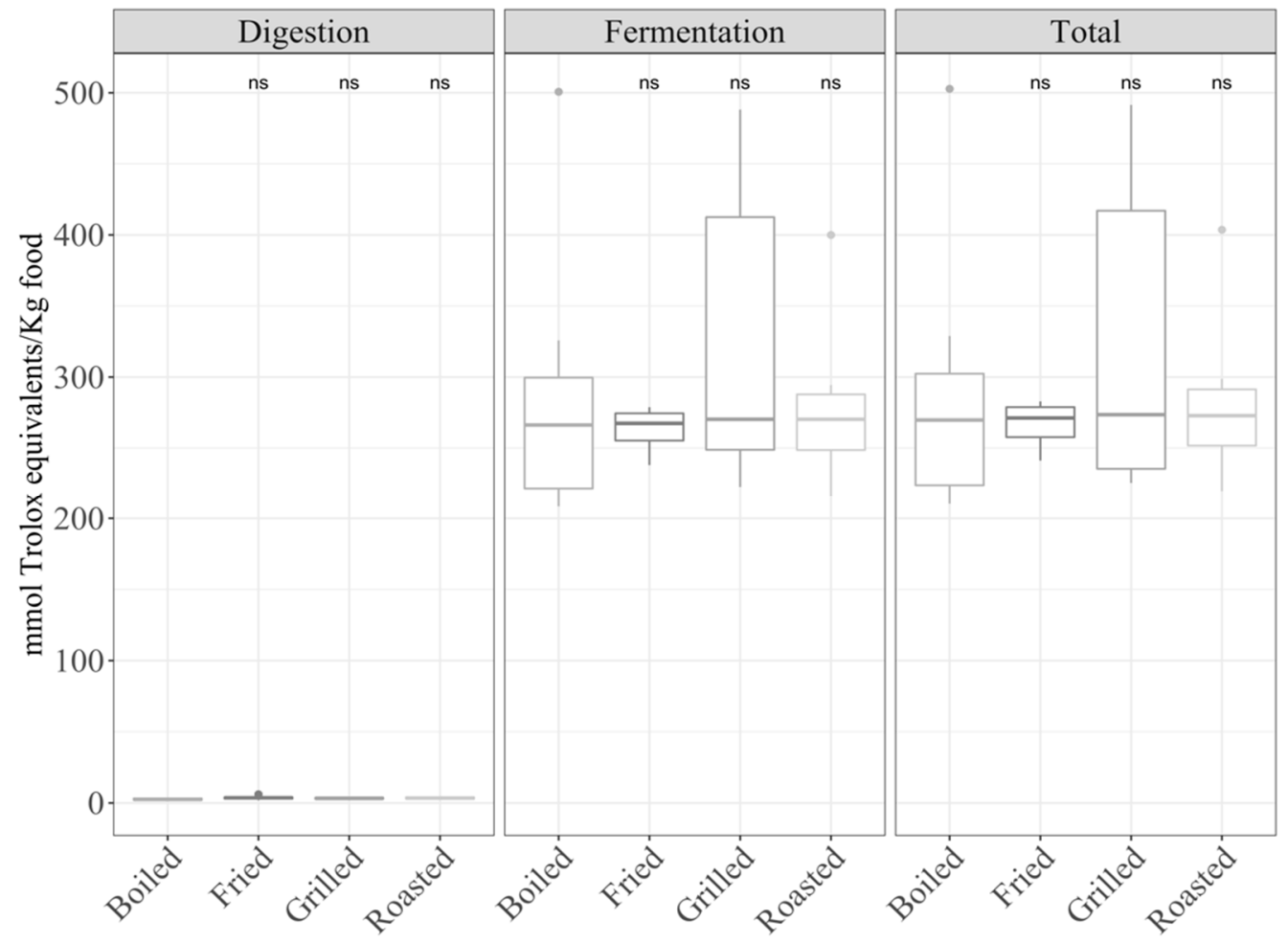

(B)
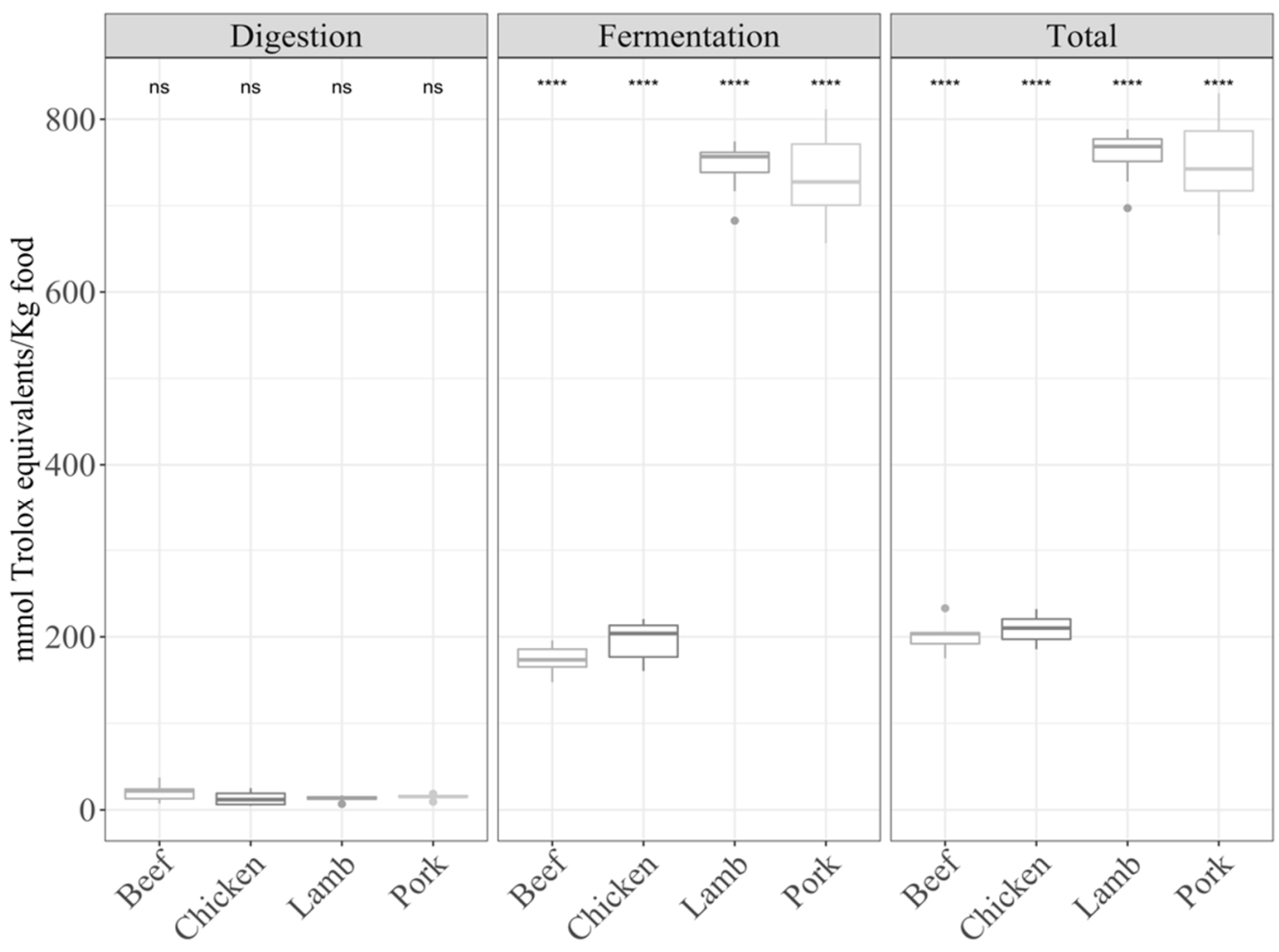

(C)

Figure 6. Cont. 


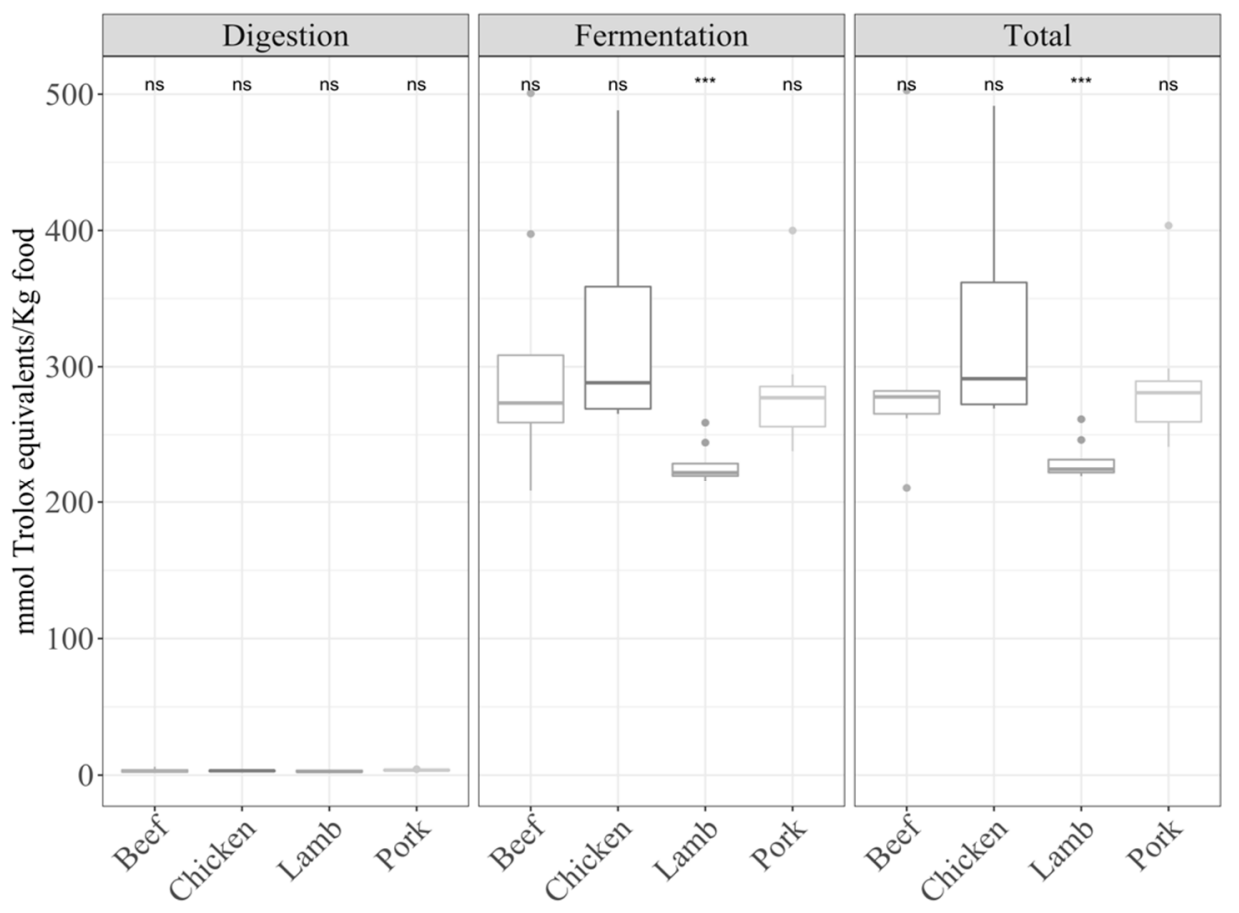

(D)
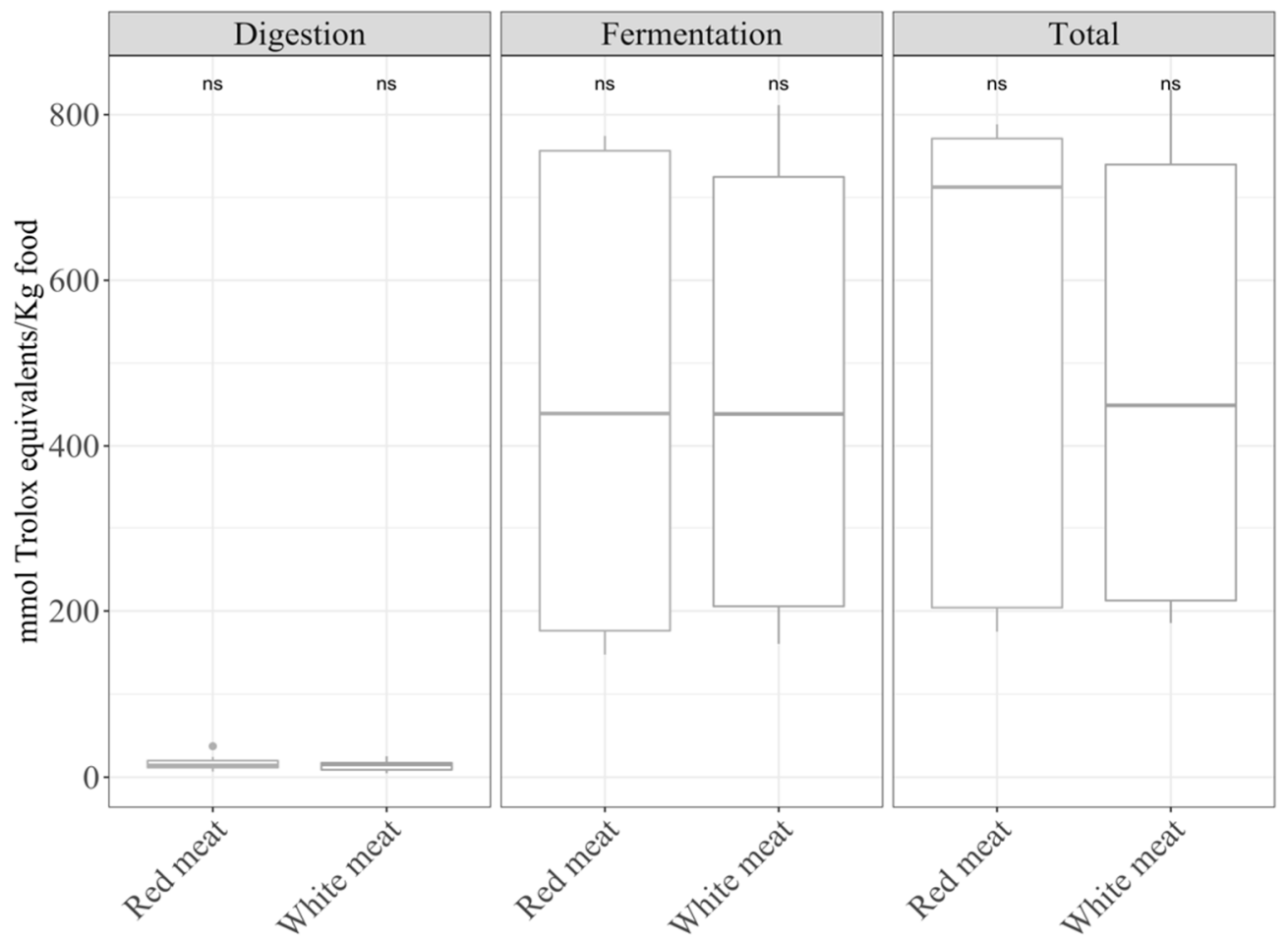

(E)

Figure 6. Cont. 


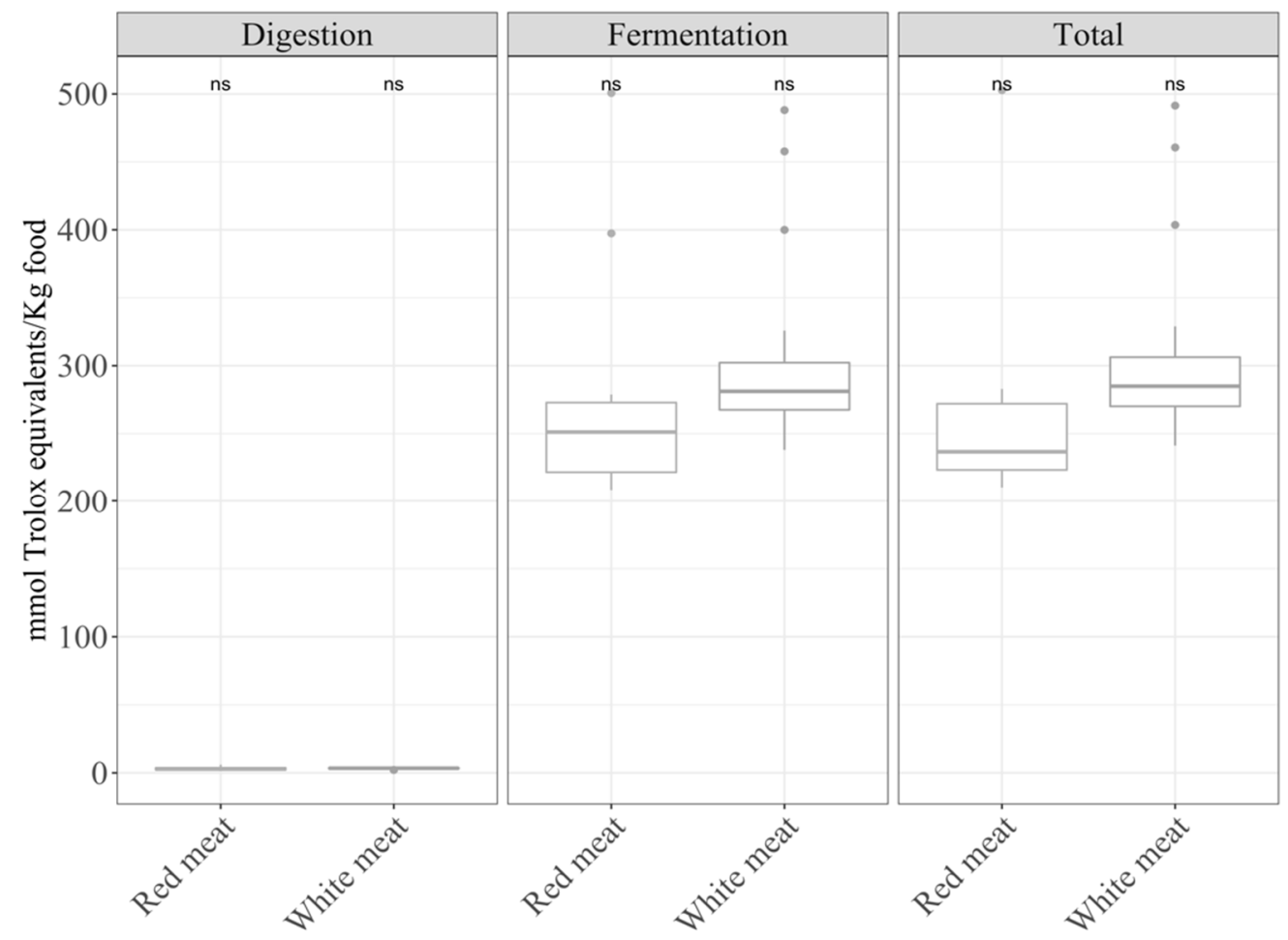

(F)

Figure 6. Antioxidant capacity of digested-fermented meat (beef, chicken, lamb, and pork) depending on the cooking

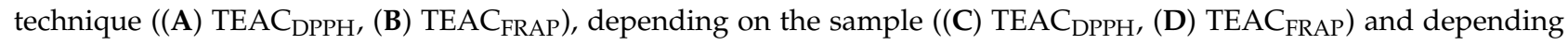
of the type of meat, red or white $\left((\mathrm{E}) \mathrm{TEAC}_{\mathrm{DPPH}},(\mathrm{F}) \mathrm{TEAC}_{\mathrm{FRAP}}\right)$. Statistical analysis was performed through ANOVA using raw vegetables or mean of all food groups as the reference group. Statistic labels: ${ }^{* * *}: p<0.001,{ }^{* * * *}: p<0.0001$, ns: not significant.

\subsection{Daily Antioxidant Intake}

We first calculated the contribution of animal food consumption to the daily antioxidant capacity intake, taking into account just the consumption of food of animal origin (Tables 1 and 2), so that their sum reaches 100\%. Dairy products showed the highest contribution to the daily antioxidant capacity intake in the Spanish diet, ranging between $56 \%$ (DPPH assay) and 66\% (FRAP assay) of the antioxidant capacity provided by foods of animal origin. Meats also stood out with a contribution of 35\% (DPPH assay) and 23\% (FRAP assay). When we considered the antioxidant capacity computed by portion size, fish contributed with 25\% (DPPH assay) and 62\% (FRAP assay), whereas meat contributed with $43 \%$ (DPPH assay) and 45\% (FRAP assay) of the antioxidant capacity (Table 1 ).

Table 1. Contribution of food of animal origin consumption to the daily antioxidant capacity (AOX) intake in the Spanish diet.

\begin{tabular}{|c|c|c|c|c|c|}
\hline Food Type & Analytical Assay & $\begin{array}{l}\text { AOX/Daily Intake }{ }^{1} \\
\text { ( } \mu \text { mol Trolox/day) }\end{array}$ & $\begin{array}{l}\text { AOX/Serving Intake }{ }^{2} \\
\text { ( } \mu \mathrm{mol} \text { Trolox/serving) }\end{array}$ & $\begin{array}{c}\text { Mean Contribution to Daily } \\
\text { Antioxidant Intake (\%) }\end{array}$ & $\begin{array}{c}\text { Mean Contribution to Daily } \\
\text { Antioxidant Per Serving Intake (\%) }\end{array}$ \\
\hline Dairy & $D P P H$ & 49,170 & 23,198 & 56.3 & 14.1 \\
\hline Egg & $D P P H$ & 5491 & 28,871 & 6.29 & 17.6 \\
\hline Meat & $D P P H$ & 31,308 & 70,944 & 35.9 & 43.2 \\
\hline Fish & $\mathrm{DPPH}$ & 1344 & 41,173 & 1.54 & 25.1 \\
\hline Food Type & Analytical Assay & $\begin{array}{l}\text { AOX/Daily Intake }{ }^{1} \\
\text { ( } \mu \text { mol Trolox/day) }\end{array}$ & 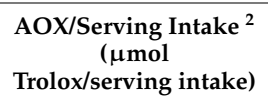 & $\begin{array}{c}\text { Mean Contribution to Daily } \\
\text { Antioxidant Intake (\%) }\end{array}$ & $\begin{array}{c}\text { Mean Contribution to Daily } \\
\text { Antioxidant Per Serving Intake (\%) }\end{array}$ \\
\hline Dairy & FRAP & 57,643 & 29,660 & 66.2 & 34.0 \\
\hline $\mathrm{Egg}$ & $F R A P$ & 7659 & 40,271 & 8.79 & 46.2 \\
\hline Meat & FRAP & 20,042 & 39,518 & 23.0 & 45.4 \\
\hline Fish & FRAP & 1765 & 54,028 & 2.03 & 62.0 \\
\hline
\end{tabular}

${ }^{1}$ Considering consumption for a whole year; ${ }^{2}$ Considering the intake of 1 serving. 
Table 2. Contribution of food of animal origin, with different culinary treatments, consumption to the daily antioxidant capacity (AOX) intake in the Spanish diet.

\begin{tabular}{|c|c|c|c|c|c|c|}
\hline $\begin{array}{l}\text { Food } \\
\text { Type }\end{array}$ & $\begin{array}{c}\text { Thermal } \\
\text { Processing }\end{array}$ & Analytical Assay & $\begin{array}{c}\text { AOX/Daily } \\
\text { Intake }^{1} \text { ( } \mu \mathrm{mol} \\
\text { Trolox/day })\end{array}$ & $\begin{array}{l}\text { AOX/Serving } \\
\text { Intake }{ }^{2} \text { ( } \mu \mathrm{mol} \\
\text { Trolox/serving) }\end{array}$ & $\begin{array}{c}\text { Mean Contribution to } \\
\text { Daily Antioxidant } \\
\text { Intake (\%) }\end{array}$ & $\begin{array}{c}\text { Mean Contribution to } \\
\text { Daily Antioxidant Per } \\
\text { Serving Intake (\%) }\end{array}$ \\
\hline Dairy & Fried & DPPH & 4319 & 8539 & 1.69 & 3.35 \\
\hline Dairy & Raw & DPPH & 4670 & 15,299 & 1.83 & 6.00 \\
\hline Dairy & Roasted & $\mathrm{DPPH}$ & 44,700 & 23,660 & 17.5 & 9.28 \\
\hline Dairy & Brewed & DPPH & 5973 & 19,564 & 2.34 & 7.68 \\
\hline Egg & Boiled & DPPH & 35,026 & 46,355 & 13.7 & 18.2 \\
\hline Egg & Fried & DPPH & 5962 & 31,351 & 2.34 & 12.3 \\
\hline$E g g$ & Grilled & DPPH & 6068 & 31,908 & 2.38 & 12.5 \\
\hline$E g g$ & Roasted & DPPH & 12,030 & 63,257 & 4.72 & 24.8 \\
\hline Meat & Boiled & DPPH & 6574 & 34,568 & 2.58 & 13.6 \\
\hline Meat & Fried & $\mathrm{DPPH}$ & 32,686 & 72,016 & 12.8 & 28.3 \\
\hline Meat & Grilled & DPPH & 30,649 & 70,579 & 12.0 & 27.7 \\
\hline Meat & Roasted & DPPH & 28,329 & 82,381 & 11.1 & 32.3 \\
\hline Fish & Boiled & DPPH & 31,625 & 71,840 & 12.4 & 28.2 \\
\hline Fish & Fried & DPPH & 1320 & 40,085 & 0.52 & 15.7 \\
\hline Fish & Grilled & DPPH & 1320 & 41,083 & 0.52 & 16.1 \\
\hline Fish & Raw & DPPH & 1460 & 44,605 & 0.57 & 17.5 \\
\hline Fish & Roasted & DPPH & 969 & 50,549 & 0.38 & 19.8 \\
\hline Dairy & Fried & FRAP & 7552 & 14,410 & 3.42 & 6.53 \\
\hline Dairy & Raw & FRAP & 41,077 & 23,419 & 18.6 & 10.6 \\
\hline Dairy & Roasted & FRAP & 5973 & 19,564 & 2.71 & 8.87 \\
\hline Dairy & UHT & FRAP & 35,026 & 46,355 & 15.9 & 21.0 \\
\hline$E g g$ & Boiled & FRAP & 5962 & 31,351 & 2.70 & 14.2 \\
\hline$E g g$ & Fried & FRAP & 6068 & 31,908 & 2.75 & 14.5 \\
\hline$E g g$ & Grilled & FRAP & 12,030 & 63,257 & 5.45 & 28.7 \\
\hline$E g g$ & Roasted & FRAP & 6574 & 34,568 & 2.98 & 15.7 \\
\hline Meat & Boiled & FRAP & 21,833 & 41,983 & 9.90 & 19.0 \\
\hline Meat & Fried & FRAP & 19,589 & 38,637 & 8.88 & 17.5 \\
\hline Meat & Grilled & FRAP & 24,088 & 45,616 & 10.9 & 20.7 \\
\hline Meat & Roasted & FRAP & 22,053 & 40,586 & 10.0 & 18.4 \\
\hline Fish & Boiled & FRAP & 1593 & 48,692 & 0.72 & 22.1 \\
\hline Fish & Fried & FRAP & 1593 & 48,939 & 0.72 & 22.2 \\
\hline Fish & Grilled & FRAP & 2191 & 63,983 & 0.99 & 29.0 \\
\hline Fish & Raw & FRAP & 969 & 50,549 & 0.44 & 22.9 \\
\hline Fish & Roasted & FRAP & 1770 & 53,802 & 0.80 & 24.4 \\
\hline
\end{tabular}

${ }^{1}$ Considering consumption for a whole year; ${ }^{2}$ Considering the intake of 1 serving.

Regarding to the cooking method applied (Table 2), roasted dairy products contributed $18 \%$ to the daily antioxidant capacity coming from foods of animal origin (DPPH assay), and raw dairy products 19\% (FRAP assay). Taking into account the consumption portion, roasted meat contributed up to $32 \%$ of the daily antioxidant capacity (DPPH assay) derived from an animal source, while grilled-roasted fish contributed 29\% (FRAP assay).

The contribution of food consumption to the daily antioxidant intake was also studied, taking into account the total diet, including also vegetable foods (Table 3) using for calculations also our results recently published regarding this type of food [14]. Taking into consideration the main food groups of the Spanish diet, it is noteworthy to mention that dairy products (35\% in DPPH assay and $28 \%$ in FRAP assay) and meat (12\% in DPPH assay and 18\% in FRAP assay) were the most antioxidant foods when the daily intake was computed. If the serving size were used, the contribution to the daily antioxidant capacity was slightly modified for meat (24\% in DPPH assay and $40 \%$ in FRAP assay) and fish (32\% in DPPH assay and 23\% in FRAP assay). Thus, in the case of the DPPH method, the top five food groups contributing to the daily antioxidant intake per serving were fish $>$ egg $>$ meat tubers $>$ fruits. In the case of the FRAP method: meat $>$ fish $>$ egg $>$ fruits $>$ tubers. 
Table 3. Antioxidant capacity distributed as a $\%$ of each food group in relation to the total diet.

\begin{tabular}{|c|c|c|c|c|}
\hline Type of Food & $\begin{array}{c}\text { Mean Contribution to } \\
\text { Daily Antioxidant } \\
\text { Capacity Intake (\%) } \\
\text { DPPH Assay }\end{array}$ & $\begin{array}{l}\text { Mean Contribution to } \\
\text { Daily Antioxidant } \\
\text { Capacity Per Serving } \\
\text { Intake (\%) DPPH Assay }\end{array}$ & $\begin{array}{c}\text { Mean Contribution to } \\
\text { Daily Antioxidant } \\
\text { Capacity Intake (\%) } \\
\text { FRAP Assay }\end{array}$ & $\begin{array}{l}\text { Mean Contribution to } \\
\text { Daily Antioxidant } \\
\text { Capacity Per Serving } \\
\text { Intake (\%) FRAP Assay }\end{array}$ \\
\hline Dairy & 35.1 & 18.1 & 28.1 & 13.2 \\
\hline$E g g$ & 4.70 & 24.5 & 3.10 & 16.5 \\
\hline Meat & 12.2 & 24.1 & 17.9 & 40.5 \\
\hline Fish & 1.10 & 32.9 & 0.80 & 23.5 \\
\hline Alcoholic drinks ${ }^{1}$ & 0.70 & 2.20 & 4.40 & 10.1 \\
\hline Cereals ${ }^{1}$ & 13.6 & 3.90 & 12.7 & 3.40 \\
\hline Cocoa ${ }^{1}$ & 0.60 & 4.20 & 0.60 & 4.60 \\
\hline Coffee $^{1}$ & 0.20 & 0.90 & 0.60 & 2.80 \\
\hline Fruits ${ }^{1}$ & 11.6 & 13.5 & 12.1 & 15.1 \\
\hline Legumes $^{1}$ & 0.80 & 10.1 & 0.70 & 9.20 \\
\hline Nuts ${ }^{1}$ & 0.80 & 3.50 & 0.70 & 2.70 \\
\hline Oils 1 & 0.30 & 0.20 & 1.10 & 0.60 \\
\hline Tubers ${ }^{1}$ & 9.00 & 19.0 & 6.50 & 14.3 \\
\hline Vegetables $^{1}$ & 9.30 & 9.70 & 10.7 & 9.80 \\
\hline
\end{tabular}

\section{Discussion}

In most cases, heat treatment positively affects the antioxidant capacity of food [21-23]. In this study, foods subjected to different cooking techniques were compared with their raw form. It was found that cooking generally increased the antioxidant capacity of foods, especially fried foods. Similar results have been found in other studies [24-26] that claim that olive oil used for frying provides a high antioxidant capacity to the preparation. However, some cooking techniques, such as boiling, could result in a loss of hydrosoluble compounds in the cooking water, such as B vitamins, and therefore antioxidant capacity could be reduced [21].

The highest antioxidant capacity was obtained after in vitro fermentation of foods (more than $90 \%$ of the total antioxidant capacity). This is an important result of our study, since in vitro fermentation potentially release-transform bioactive compounds with high antioxidant capacity. Therefore, the gut microbiota seems to play an important role in the release of these compounds from the indigestible matrix of animal-derived foods [24,25], as in the case of plant-derived foods [14]. Heat treatment catalyzes different chemical reactions such the Maillard reaction [27-29]. In this sense, cooking techniques with a high heat-load (i.e., frying, grilling, and roasting) can produce a large amount of melanoproteins [30,31], which are end-products of the Maillard reaction with a high antioxidant capacity [32]. Such melanoidins are hardly digested and reach the colon, where they are metabolized by the gut microbiota [33].

The antioxidant capacity of digested meats (beef, chicken, lamb, and pork) ranged from 13.2 to $20.5 \mathrm{mmol}$ Trolox equivalents $/ \mathrm{Kg}$ meat (Table S10), which is in line with values reported by other authors [26]. However, the study reported by Carrillo et al. [26] doesn't include the antioxidant capacity obtained after in vitro fermentation, which is up to $95 \%$ higher, reinforcing the idea that the fermentation step is needed to check the overall antioxidant potential of a given food. Lamb and pork meats were the most antioxidant meats with the DPPH method, while lamb was the lowest one with the FRAP assay (Table S10). This could be related to the poor ability of lamb antioxidants to reduce ferric ion to its ferrous form instead of quenching radical species [26]. In addition, although the antioxidant capacity of digested meat and fish was similar (Table S3) the final antioxidant capacity of meat was higher, since more antioxidant compounds could be released after fermentation. These differences could come from the feed that these animals have. The feeding of meat-producing animals is more controlled than that of fish, and they may have been fed feeds rich in compounds with antioxidant activity [10].

In the group of dairy products, butter stood out as the food with the greatest antioxidant capacity. This could be explained, taking into account that some antioxidant 
compounds in dairy products (such as $\alpha$-tocopherol, $\beta$-carotene, vitamins $A$ and $\mathrm{D}_{3}$, and phospholipids) are found in milk fat, the main component of butter [11].

Among all the foods chosen for this study, meat stood out for its antioxidant capacity, while dairy products and fish had the lowest values, which doesn't mean that their contribution to the antioxidant capacity intake with the diet is also lower. The antioxidant capacity provided by each food was studied, taking into account daily consumption in a regular diet [19], as well as portion sizes [20] (Table 1). In Table 2, the culinary treatments applied were also taken into account. Dairy products, which are highly consumed by the Spanish population [19], stood out for their daily intake, as well as roasted meat and grilled fish.

Till now, the efforts on calculating the contribution of the regular diet to the daily antioxidant intake have been centered in plant foods [16,34], since they provide many bioactive antioxidant compounds such as phenolic compounds, vitamins, etc. Thus, our results cannot be compared with other papers on the matter, since there is no scientific literature about the contribution of animal foods to the daily antioxidant capacity. However, foods of animal origin are also a good source of antioxidant compounds like dipeptides (carnosine and anserine), uric acid, polyamines, ascorbic acid, $\alpha$-tocopherol, B group vitamins, carotenoids, ubiquinone, among others [26]. This is why we calculated the overall contribution of the Spanish diet to the daily antioxidant capacity (Table 3), taking into account the intake of animal origin foods (data reported in the paper) and plant foods [14]. The first interesting result is that the Spanish diet provides an average of 175.1 (DPPH) and 164.3 (FRAP) mmol Trolox/day, which is much higher than that previously reported [34] for vegetable products only (6.1 mmol Trolox/day). This could be explained by taking into account that the initials calculations performed by Saura-Calixto and Goñi [33] were computed with the usual extraction method of antioxidant species, avoiding the large effects of digestion and fermentation. In addition, it is noteworthy to mention that the contribution of animal foods was notable $(49.7 \%$ and $53.1 \%$ of the total antioxidant capacity intake for DPPH and FRAP methods), reaching 87.1 and $87.3 \mathrm{mmol}$ Trolox/day for DPPH and FRAP assays, respectively. The food groups with a higher contribution to the daily antioxidant capacity intake of the Spanish diet were as follows: dairy $>$ cereals $>$ meat $>$ fruits $>$ vegetables $>$ tubers $>$ egg $(\mathrm{DPPH})$ and dairy $>$ meat $>$ cereals $>$ fruits $>$ vegetables $>$ tubers $>$ egg (FRAP). However, if an increase in antioxidant capacity intake should be recommended, them the food groups suggested (due to the high antioxidant capacity provided by a portion) will be: fish $>$ egg $>$ meat $>$ tubers $>$ dairy $>$ vegetables (DPPH) and meat $>$ fish $>$ egg $>$ fruits $>$ tubers $>$ dairy.

\section{Conclusions}

In conclusion, this study reinforces the concept that foods of animal origin could be considered as a good source of antioxidant compounds for humans. This research has demonstrated that though animal origin food may not be rich in bioactive antioxidant components (like plant foods) gastrointestinal digestion and, more importantly, gut microbiota fermentation, can improve the antioxidant properties of such foods. Most of the antioxidant power of these foodstuffs was released subsequent to in vitro gut microbiota fermentation (around 90\%). The food groups with the highest antioxidant capacity were meat and fish, which were increased even more after frying and boiling. The foods that contributed the most antioxidant capacity to the diet in terms of daily consumption were dairy products, while in terms of portion size, the foods with the highest antioxidant capacity were meat and fish. Therefore, the daily antioxidant capacity intake in the Spanish diet has been revisited, finding that foods of animal origin contribute to around $50 \%$ of the daily antioxidant capacity intake. So, further studies on antioxidant capacity involving foods of animal origin after in vitro digestion and fermentation should be carried out in the future in order to estimate their contribution to the daily intake of antioxidant capacity.

Supplementary Materials: The following are available online at https:/ / www.mdpi.com/2076-392 1/10/3/445/s1, Supplemental Table S1. Food of animal origin and cooking conditions. Supplemental 
Table S2. Antioxidant capacity of in vitro digested-fermented foods of animal origin depending on the cooking method. Supplemental Table S3. Antioxidant capacity of in vitro digested-fermented foods of animal origin depending on the group. Supplemental Table S4. Antioxidant capacity of in vitro digested-fermented dairy foods depending on the cooking method. Supplemental Table S5. Antioxidant capacity of in vitro digested-fermented dairy foods depending on the dairy type. Supplemental Table S6. Antioxidant capacity of in vitro digested-fermented fish depending on the cooking method. Supplemental Table S7. Antioxidant capacity of in vitro digested-fermented fish depending on the fish type. Supplemental Table S8. Antioxidant capacity of in vitro digestedfermented meat depending on the cooking method. Supplemental Table S9. Antioxidant capacity of in vitro digested-fermented meat depending on the meat type. Supplemental Table S10. Antioxidant capacity of in vitro digested-fermented red and white meat.

Author Contributions: Conceptualization, S.P. and J.Á.R.-H.; methodology, S.P.-B. and D.H.-N.; validation, S.P.-B., B.N.-P. and Á.V.-M.; formal analysis, B.N.-P. and Á.V.-M.; investigation, D.H.-N., S.P. and J.Á.R.-H.; data curation, S.P.-B.; writing-original draft preparation, B.N.-P. and Á.V.-M.; writing-review and editing, S.P.-B., S.P. and J.Á.R.-H.; supervision, S.P.-B. and J.Á.R.-H.; project administration, J.Á.R.-H.; funding acquisition, J.Á.R.-H. All authors have read and agreed to the published version of the manuscript.

Funding: This work was supported by the European Research Commission (Research Executive Agency) under de research project Stance4Health (Grant contract $\mathrm{N}^{\circ}$ 816303) and by the Plan propio de Investigación y Transferencia of the University of Granada under the program "Intensificación de la Investigación, modalidad B".

Institutional Review Board Statement: The study was conducted according to the guidelines of the Declaration of Helsinki, and approved by the Ethics Committee of the University of Granada (protocol code 1080/CEIH/2020).

Informed Consent Statement: Informed consent was obtained from all subjects involved in the study.

Data Availability Statement: The data presented in this study are available as supplementary material.

Acknowledgments: This work is part of the thesis of Beatriz Navajas-Porras to obtain the PhD in the Nutrition and Food Sciences program at the University of Granada.

Conflicts of Interest: The authors declare no conflict of interest.

\section{References}

1. Sotos Prieto, M.; Guillen, M.; Sorlí, J.V.; Asensio, E.M.; Gillem Sáiz, P.; González, J.I.; Corella, D. Consumo de Carne y Pescado En Población Mediterránea Española de Edad Avanzada y Alto Riesgo Cardiovascular. Nutr. Hosp. 2011, 26, 1033-1040. [CrossRef] [PubMed]

2. Yip, C.S.C.; Lam, W.; Fielding, R. A Summary of Meat Intakes and Health Burdens. Eur. J. Clin. Nutr. 2018, 72, 18-29. [CrossRef]

3. Olmedilla-Alonso, B.; Jiménez-Colmenero, F.; Sánchez-Muniz, F.J. Development and Assessment of Healthy Properties of Meat and Meat Products Designed as Functional Foods. Meat Sci. 2013, 95, 919-930. [CrossRef]

4. Abuajah, C.I.; Ogbonna, A.C.; Osuji, C.M. Functional Components and Medicinal Properties of Food: A Review. J. Food Sci. Technol. 2015, 52, 2522-2529. [CrossRef]

5. Leri, M.; Scuto, M.; Ontario, M.L.; Calabrese, V.; Calabrese, E.J.; Bucciantini, M.; Stefani, M. Healthy Effects of Plant Polyphenols: Molecular Mechanisms. Int. J. Mol. Sci. 2020, 21, 1250. [CrossRef] [PubMed]

6. Pimentel, F.A.; Nitzke, J.A.; Klipel, C.B.; Jong, E.V. de chocolate and red wine-A comparison between flavonoids content. Food Chem. 2010, 120, 109-112. [CrossRef]

7. Marcolini, E.; Babini, E.; Bordoni, A.; Di Nunzio, M.; Laghi, L.; Maczó, A.; Picone, G.; Szerdahelyi, E.; Valli, V.; Capozzi, F. Bioaccessibility of the Bioactive Peptide Carnosine during in Vitro Digestion of Cured Beef Meat. J. Agric. Food Chem. 2015, 63, 4973-4978. [CrossRef] [PubMed]

8. Xing, L.; Chee, M.E.; Zhang, H.; Zhang, W.; Mine, Y. Carnosine-A Natural Bioactive Dipeptide: Bioaccessibility, Bioavailability and Health Benefits. J. Food Bioact. 2019, 5, 8-17. [CrossRef]

9. Radzik-Rant, A.; Rant, W.; Sosnowiec, G.; Świątek, M.; Niżnikowski, R.; Szymańska, Ż. The Effect of Genotype and Muscle Type on the Physico-Chemical Characteristics and Taurine, Carnosine and L-Carnitine Concentration in Lamb Meat. Arch. Anim. Breed. 2020, 63, 423-430. [CrossRef]

10. Chen, D.; Wu, M.; Xie, S.; Li, X.; Tao, Y.; Wang, X.; Huang, L.; Pan, Y.; Peng, D.; Yuan, Z. Determination of Tartrazine, Lutein, Capsanthin, Canthaxanthin and $\beta$-Carotene in Animal-Derived Foods and Feeds by HPLC Method. J. Chromatogr. Sci. 2019, 57, 462-468. [CrossRef] 
11. Grażyna, C.; Hanna, C.; Adam, A.; Magdalena, B.M. Natural Antioxidants in Milk and Dairy Products. Int. J. Dairy Technol. 2017, 70, 165-178. [CrossRef]

12. Pérez-Burillo, S.; Rufián-Henares, J.A.; Pastoriza, S. Towards an improved global antioxidant response method (GAR+): Physiological-resembling in vitro antioxidant capacity methods. Food Chem. 2018, 239, 1263-1272. [CrossRef]

13. Agans, R.; Gordon, A.; Kramer, D.L.; Pérez-Burillo, S.; Rufián-Henares, J.A.; Paliy, O. Dietary Fatty Acids Sustain the Growth of the Human Gut Microbiota. Appl. Environ. Microbiol. 2018, 84, e01525-18. [CrossRef] [PubMed]

14. Navajas-Porras, B.; Pérez-Burillo, S.; Valverde-Moya, Á.J.; Hinojosa-Nogueira, D.; Pastoriza, S.; Rufián-Henares, J.Á. Effect of Cooking Methods on the Antioxidant Capacity of Plant Foods Submitted to In Vitro Digestion-Fermentation. Antioxidants 2020, 9, 1312. [CrossRef] [PubMed]

15. Pérez-Burillo, S.; Rufián-Henares, J.A.; Pastoriza, S. Towards an Improved Global Antioxidant Response Method (GAR+): Physiological-Resembling in vitro Digestion-Fermentation Method. Food Chem. 2018, 239, 1253-1262. [CrossRef] [PubMed]

16. Pastoriza, S.; Delgado-Andrade, C.; Haro, A.; Rufián-Henares, J.A. A Physiologic Approach to Test the Global Antioxidant Response of Foods. The GAR Method. Food Chem. 2011, 129, 1926-1932. [CrossRef]

17. Rapisarda, P.; Tomaino, A.; Lo Cascio, R.; Bonina, F.; De Pasquale, A.; Saija, A. Antioxidant Effectiveness as Influenced by Phenolic Content of Fresh Orange Juices. J. Agric. Food Chem. 1999, 47, 4718-4723. [CrossRef]

18. Benzie, I.F.F.; Strain, J.J. The Ferric Reducing Ability of Plasma (FRAP) as a Measure of "Antioxidant Power": The FRAP Assay. Anal. Biochem. 1996, 239, 70-76. [CrossRef]

19. Mercasa. La Alimentación en España. 2020. Available online: https://www.mercasa.es/media/publicaciones/281/AEE_2020 web.pdf (accessed on 15 January 2021).

20. Salvador i Castells, G. Tabla de Medidas Caseras de Alimentos. In Nutrición y Dietética Clínica; Salas-Salvadó, J., Bonada, A., Trallero, R., Saló, M.E., Eds.; Elsevier-Masson: Barcelona, Spain, 2000; pp. 557-570.

21. Ramírez-Anaya, J.P.; Samaniego-Sánchez, C.; Castañeda-Saucedo, M.C.; Villalón-Mir, M.; de la Serrana, H.L.-G. Phenols and the antioxidant capacity of Mediterranean vegetables prepared with extra virgin olive oil using different domestic cooking techniques. Food Chem. 2015, 188, 430-438. [CrossRef]

22. Miglio, C.; Chiavaro, E.; Visconti, A.; Fogliano, V.; Pellegrini, N. Effects of different cooking methods on nutritional and physicochemical characteristics of selected vegetables. J. Agric. Food Chem. 2008, 56, 139-147. [CrossRef]

23. Rufián-Henares, J.A.; Guerra-Hernández, E.; García-Villanova, B. Effect of Red Sweet Pepper Dehydration Conditions on Maillard Reaction, Ascorbic Acid and Antioxidant Activity. J. Food Eng. 2013, 118, 150-156. [CrossRef]

24. Pérez-Burillo, S.; Rufián-Henares, J.A.; Pastoriza, S. Effect of Home Cooking on the Antioxidant Capacity of Vegetables: Relationship with Maillard Reaction Indicators. Int. Food Res. J. 2019, 121, 514-523. [CrossRef]

25. Pérez-Burillo, S.; Pastoriza, S.; Jiménez-Hernández, N.; D’Auria, G.; Francino, M.P.; Rufián-Henares, J.A. Effect of Food Thermal Processing on the Composition of Gut Microbiota. J. Agric. Food Chem. 2018, 66, 11500-11509. [CrossRef]

26. Carrillo, C.; Barrio, A.; Cavia, M.M.; Alonso-Torre, S. Global antioxidant response of meat. J. Sci. Food Agric. 2017, 97, 2358-2365. [CrossRef]

27. Rufián-Henares, J.A.; Guerra-Hernández, E.; García-Villanova, B. Colour measurement as indicator for controlling the manufacture and storage of enteral formulas. Food Cont. 2006, 17, 489-493. [CrossRef]

28. Delgado-Andrade, C.; Rufián-Henares, J.A.; Morales, F.J. Lysine availability is diminished in commercial fibre-enriched breakfast cereals. Food Chem. 2007, 100, 725-731. [CrossRef]

29. Pastoriza de la Cueva, S.; Álvarez, J.; Végvári, Á.; Montilla-Gómez, J.; Cruz-López, O.; Delgado-Andrade, C.; Rufián-Henares, J.A. Relationship between HMF intake and SMF formation in vivo: An animal and human study. Mol. Nutr. Food Res. 2017, 61, 1600773. [CrossRef]

30. Zhou, Y.; Xie, F.; Zhou, X.; Wang, Y.; Tang, W.; Xiao, Y. Effects of Maillard reaction on flavor and safety of Chinese traditional food: Roast duck. J. Sci. Food Agric. 2016, 96, 1915-1922. [CrossRef]

31. Rodríguez, A.; Lema, P.; Bessio, M.I.; Moyna, G.; Panizzolo, L.A.; Ferreira, F. Isolation and Characterization of Melanoidins from Dulce de Leche, A Confectionary Dairy Product. Molecules 2019, 24, 4163. [CrossRef]

32. Gu, F.L.; Kim, J.M.; Abbas, S.; Zhang, X.M.; Xia, S.Q.; Chen, Z.X. Structure and antioxidant activity of hugh molecular Maillard reaction products from casein-glucose. Food Chem. 2010, 120, 505-511. [CrossRef]

33. Tagliazucchi, D.; Bellesia, A. The gastro-intestinal tract as the major site of biological action of dietary melanoidins. Amino Acids 2015, 47, 1077-1089. [CrossRef] [PubMed]

34. Saura-Calixto, F.; Goñi, I. Antioxidant capacity of the Spanish Mediterranean diet. Food Chem. 2006, 94, 442-447. [CrossRef] 